\title{
MiR-612 regulates invadopodia of hepatocellular carcinoma by HADHA- mediated lipid reprogramming
}

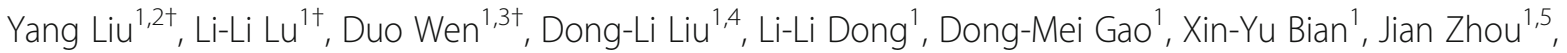
Jia Fan ${ }^{1,5^{*}}$ and Wei-Zhong $\mathrm{Wu}^{1 *}$

\begin{abstract}
Background: MicroRNA-612 (miR-612) has been proven to suppress EMT, stemness, and tumor metastasis of hepatocellular carcinoma (HCC) via PI3K/AKT2 and Sp1/Nanog signaling. However, its biological roles on HCC progression are far from elucidated.
\end{abstract}

Methods: We found direct downstream target of miR-612, hadha by RNA immunoprecipitation and sequencing. To explore its biological characteristic, potential molecular mechanism, and clinical relevance in HCC patients, we performed several in-vitro and in-vivo models, as well as human tissue chip.

Results: Ectopic expression of miR-612 could partially reverse the level of HADHA, then suppress function of pseudopods, and diminish metastatic and invasive potential of HCC by lipid reprogramming. In detail, miR-612 might reduce invadopodia formation via HADHA-mediated cell membrane cholesterol alteration and accompanied with the inhibition of Wnt/ $\beta$-catenin regulated EMT occurrence. Our results showed that the maximum oxygen consumption rates (OCR) of HCCLM3 $3^{\text {miR-612-OE }}$ and HCCLM3 $3^{\text {hadha-KD }}$ cells were decreased nearly by $40 \%$ and $60 \%$ of their counterparts $(p<0.05)$. The levels of acetyl CoA were significantly decreased, about $1 / 3(p>0.05)$ or $1 / 2(p<$ 0.05 ) of their controls, in exogenous miR-612 or hadha-shRNA transfected HCCLM3 cell lines. Besides,

overexpression of hadha cell lines had a high expression level of total cholesterol, especially 27-hydroxycholesterol $(p<0.005)$. SREBP2 protein expression level as well as its downstream targets, HMGCS1, HMGCR, MVD, SQLE were all deregulated by HADHA. Meanwhile, the ATP levels were reduced to $1 / 2$ and $1 / 4$ in HCCLM3 ${ }^{\text {miR-612-OE }}(p<0.05)$ and HCCLM3 ${ }^{\text {hadha-KD }}(p<0.01)$ respectively. Moreover, patients with low miR-612 levels and high HADHA levels had a poor prognosis with shorter overall survival.

Conclusion: miR-612 can suppress the formation of invadopodia, EMT, and HCC metastasis and by HADHAmediated lipid programming, which may provide a new insight of miR-612 on tumor metastasis and progression.

Keywords: miR-612, Hepatocellular carcinoma, Invadopodia, $\beta$-Oxidation, Metastasis

\section{Introduction}

Hepatocellular carcinoma (HCC) is an aggressive cancer with poor long-term survival. Every year, up to 600,000 people die from the disease in the worldwide, and it has been a serious issue to human health $[1,2]$. High recurrence and metastasis rate of $\mathrm{HCC}$ after surgical resection

\footnotetext{
*Correspondence: fan.jia@zs-hospital.sh.cn; wu.weizhong@zs-hospital.sh.cn

${ }^{\dagger}$ Yang Liu, Li-Li Lu and Duo Wen contributed equally to this work.

${ }^{1}$ Liver Cancer Institute, Zhongshan Hospital, Key Laboratory of Carcinogenesis and Cancer Invasion, Ministry of Education, Fudan University, 180 Fenglin Road, Shanghai 200032, China

Full list of author information is available at the end of the article
}

is still a Gordian knot to further improve the patients' survival. Therefore, the exploration of underlying mechanism of HCC recurrence and metastasis has been an important clinical significance for early diagnosis and intervention.

Normally, cell morphology and function are elaborately orchestrated by dynamic metabolisms of carbohydrates, lipids, and amino acids. Dysfunctions of metabolic reprogramming have been found to be an important characteristic of tumor cells during tumorigenesis and metastasis. Even in normoxia, tumor cells are

(C) The Author(s). 2020 Open Access This article is distributed under the terms of the Creative Commons Attribution 4.0 International License (http://creativecommons.org/licenses/by/4.0/), which permits unrestricted use, distribution, and 
inclined to produce ATP by glycolysis, which is called as aerobic glycolysis or Warburg effects [3]. Although less efficient than oxidative phosphorylation, tumor cells usually turnover glucoses quickly in glycolytic pathway to meet their aggressive needs on energy and produce an intermediate, glutamine, the fastest-consuming amino acid in tumor microenvironment [4]. The latter may provide carbon and nitrogen sources for de novo syntheses of amino acids, nucleotides, and lipids. Recently, many evidences suggest that the abnormities of lipidand cholesterol-metabolisms are also involved in tumorigenesis and progression. Lipids are reported to be another important energy source to fuel tumor metastasis [5]. Lipids, together with cholesterol, could form lipid rafts on cell membrane where a lot of receptors, ligands, and iron-channel proteins are aggregated as a functional unit. Destruction of lipid rafts is enough to prevent cell proliferation and tumor growth [6]. In addition, invadopodia, another prominent membranous structure in migrated and invasive cancer cells, is closely regulated by lipid- and cholesterol-metabolisms. The cholesterolbiosynthesis pathway is under tight regulation by transcription factors, such as sterol regulatory elementbinding protein 1 and 2 (SREBP1 and 2). The accumulation of SREBP2 in nucleus binds to sterol response elements (SREs) to activate the expression of cholesterolbiosynthesis enzymes, such as 3-hydroxy-3-methylglutaryl-CoA reductase (HMGCR) and squalene epoxidase (SQLE) [7]. Whether this cascade could regulate cholesterol metabolism and invadopodia formation of $\mathrm{HCC}$ cells were still unknown. In virtue of invadopodia, cancer cells can degrade extracellular matrix, penetrate through blood vessels, and finally disseminate into distant target organs [8]. Due to its important roles in tumor metastasis, a lot of components and regulators of invadopodia, such as integrins, actin-binding proteins, scaffolders [9, $10]$, as well as signaling adaptors, are widely studied [11]. However, the roles of lipid metabolisms on the formation and the function of invadopodia in $\mathrm{HCC}$ still need to be unveiled.

Non-coding RNAs (ncRNAs) have emerged as one important kind of molecules that can regulate altered genes contributing, to the establishment of metabolic reprogramming [12]. For instance, SNHG16 could be regulated by the Wnt pathway in colorectal cancer and affect genes involved in lipid metabolism [13]. HULC functions as an oncogene in hepatoma cells, acting mechanistically by deregulating lipid metabolism through a signaling pathway involving miR-9, PPARA, and ACSL1 [14]. MicroRNAs (miRNAs), as a class of endogenous small noncoding RNAs, can regulate target protein expression at posttranscriptional level $[15,16]$. To date, multiple miRNAs have been discovered to involve in the regulation of lipid metabolism, such as miR-30c, miR-122, etc.
$[17,18]$. In our previous study, miR-612 was found to have robustly suppressive effects on HCC proliferation and metastasis [19]. And 167 genes were predicted as potential targets of miR-612 by miRanda, TargetScan, and miRTarget2. Two pivotal genes were drawn out from these predicted genes in gene interaction network based on function enrichment analysis (Additional file 1: Figure $\mathrm{S} 1 \mathrm{~A}$ ). One is $a k t 2$, which has been confirmed to mediate the suppressive effects of miR-612 in HCC invasive-metastatic cascade in our previously study. The other is hadha, whose roles in HCC metastasis are unknown by far. As hadha encodes the alpha subunit of mitochondrial trifunctional protein, hydroxyacyl-CoA dehydrogenase/3-ketoacyl-CoA thiolase/enoyl-CoA hydratase, the enzyme complex catalyze the three steps of beta-oxidation of fatty acids in mitochondria: longchain 3-hydroxyacyl-CoA dehydrogenase (LCHAD), long-chain enoyl-CoA hydratase, and long-chain thiolase activities [20]. Therefore, we supposed that miR-612 might regulate tumor invasiveness and metastasis by HADHA-mediated lipid reprogramming and probably resulting in the abnormity of invadopodia in structure and function in HCC.

In this study, we mainly focused the roles of miR-612 on lipid reprogramming, invasiveness, and metastasis of HCC, which may lay a basis for its clinical application in precision diagnosis and therapy of metastatic HCC.

\section{Materials and methods}

\section{Cell lines and cell culture}

Human HCC cell line, HCCLM3, was established at the Liver Cancer Institute, Zhongshan Hospital, Fudan University, Shanghai, China [21, 22]. HepG2 cell line was purchased from the Shanghai Cell Bank, Chinese Academy of Sciences (CAS). HCCLM3 cells express low endogenous levels of miR-612 with relatively high metastatic potentials, whereas HepG2 cells express high endogenous levels of miR-612 with low metastatic potentials [19, 23, 24]. We transiently transfected with miR-612 mimic oligonucleotides (mimics) or inhibitory oligonucleotides (inhibitors) into HCCLM3 or HepG2 cells. hU6-MCS-CMV-shRNA-eGFP and Ubi-MCSHADHA-3FLAG-SV40-Cherry lentiviral vectors were purchased from Genomeditech (Shanghai, China). They were transfected into HCCLM3 or HepG2 cells, respectively. The target sequences of si-HADHA was TGGTGA CAAGATTTGTGAA, and HADHA-cDNA primer sequences were listed as follows: Forward: GAGGAT CCCCGGGTACCGGTCGCCACCATGGCGGAGCC GAGCGGC; Reward: TCACCATGGTGGCGACCG GGCTGACACTCAACTGAGCA. All negative control cells either with mocked oligonucleotides or mockedshRNA or mocked-cDNA lentiviral vectors were named as HCCLM3 ${ }^{\mathrm{NC}}$ and HepG2 ${ }^{\mathrm{NC}}$. Wild-type (WT) cell lines 
were with no treatments. All these cells were cultured under standard conditions, DMEM (GE, Utah, USA) supplemented with $10 \%$ FBS (GE, Utah, USA), penicillin $(100 \mathrm{IU} / \mathrm{ml})$, and streptomycin sulfate $(100 \mu \mathrm{g} / \mathrm{ml})$ and routinely maintained in a humidified incubator at $5 \%$ $\mathrm{CO}_{2}$ at $37^{\circ} \mathrm{C}$.

\section{Gelatin invadopodia assay}

$\mathrm{QCM}^{\mathrm{TM}}$ gelatin invadopodia assay (No.ECM671, Millipore, MA, USA) was used for rapid detection of matrix degradation [25]. In belief, $2 \times 10^{4} / 500 \mu \mathrm{l}$ of HCC cells were added into glass dish pre-prepared with fluorescent substrate. Then the cells were cultured in the dark at room temperature for 15-30 min and sequentially in an incubator for $48 \mathrm{~h}$. After fixed with 3.7\% formaldehyde for $30 \mathrm{~min}$, and stained with FITC-phalloidin and DAPI in blocking/permeabilization buffer for $1 \mathrm{~h}$ respectively, the cells were removed from staining solution and rinsed twice with fluorescent staining buffer using $500 \mu \mathrm{l} /$ well. Laser scanning confocal microscope-TCS SP5 (Leica) was used to capture images.

\section{$\beta$-oxidation activity detection}

HCC cells were cultured in XF 96-well microplate. The medium was replaced $24 \mathrm{~h}$ before the experiment and the cells were washed twice with the FAO assay medium $45 \mathrm{~min}$ before the assay. Fifteen microliter per well $40 \mathrm{mM}$ Eto was added in a column of cells as positive control group and incubated for $15 \mathrm{~min}$ at $37{ }^{\circ} \mathrm{C}$ in a $\mathrm{CO}_{2}$ free incubator. One hundred thirty five microliter per well of FAO assay medium was added to the cells and continued to incubate for $30-45 \mathrm{~min}$. The XF cell culture microplate was inserted into the XF96 analyzer to detect. $2.5 \mu \mathrm{g} / \mathrm{ml}$ oligomycin (oligo), $1.6 \mu \mathrm{M}$ FCCP, and $2 \mu \mathrm{M}$ Rotenone/4 $\mu \mathrm{M}$ Antimycin A (Rtn/AA) were added to the cell cultures at $22 \mathrm{~min}, 38 \mathrm{~min}$, and $52 \mathrm{~min}$ in order.

\section{ATP assay}

ATP level in sample was tested by a commercial kit (No. A095, Jiancheng Bioengineering Institute, Nanjing, China). In brief, $10^{6}$ of cell pellets were re-suspended in

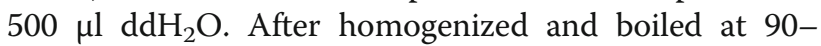
$100{ }^{\circ} \mathrm{C}$ for $10 \mathrm{~min}$, the mixture was vortexed and centrifuged. The supernatant was collected to set up a reaction system as described in Additional file 5: Table S3. The OD value of each sample was measured by spectrophotometer $(\lambda=636 \mathrm{~nm})$. The ATP level $(\mu \mathrm{mol} / \mathrm{g})=\left(\mathrm{OD}_{\text {mea- }}\right.$ sured $\left.-\mathrm{OD}_{\text {control }}\right) /\left(\mathrm{OD}_{\text {standard }}-\mathrm{OD}_{\text {blank }}\right) \times$ standard concentration $\left(1 \times 10^{3} \mu \mathrm{mol} / \mathrm{L}\right) \times$ sample before dilution / sample protein concentration $(\mathrm{g} / \mathrm{l})$.

\section{Cholesterol quantitation assay}

The concentration of cholesterol was measured by Cholesterol/Cholesteryl Ester Quantitation Assay kit (No. ab65359, Abcam, MA, USA). In belief, $1 \times 10^{6}$ HCC cells with indicated treatment were centrifuged and the pellet was re-suspended in $200 \mu \mathrm{l}$ of Chloroform:Isopropanol: NP-40 (7:11:0.1) solution using a microhomogenizer. Then the liquid in organic phase was taken out and transferred into a new tube after spinned at 15,000 $\mathrm{g}$ for $10 \mathrm{~min}$, air dried at $50{ }^{\circ} \mathrm{C}$, and vacuumed for $30 \mathrm{~min}$. The dried lipids were re-dissolved in $200 \mu \mathrm{l}$ kit provided Assay Buffer by virtue of sonicator and vortex mixer, and set up a reaction system as described in Additional file 5: Table S4. The OD value of each sample was measured by spectrophotometer $(\lambda=570 \mathrm{~nm})$.

\section{Statistical analysis}

Data were analyzed using GraphPad Prism 5 software [23]. Quantitative variables were expressed as means \pm SEM and analyzed by one-way ANOVA, Student's $t$ test, Kruskal-Wallis test, or Mann-Whitney test. Qualitative variables were compared using Pearson's $\chi^{2}$ test or Fisher exact test. The log-rank test was used to determine the statistical significance of the differences between metastasis-free survival curves. R/Bioconductor software was used for all bioinformatics analysis. Results were considered statistically significant at $p<0.05$.

\section{Other materials and methods}

Details on Western blotting, RNA extraction, real-time PCR [24, 26], RNA immunoprecipitation and sequencing [27], luciferase reporter assay [28], miRNA in situ hybridization, patient selection and tissue microarray (TMA) construction [29], immunofluorescence staining, immunohistochemical staining [30], and functional assays, such as migration, and Matrigel invasion assays [19], wound healing assays [31], in vivo assays for tumor metastasis [32, 33], cell membrane fluidity evaluated by TMA-DPH, statistical analysis [28], are described in the Additional file 6.

\section{Results \\ Low endogenous miR-612 level correlates with poor outcome of patients}

In our previous study, we have noticed that the level of miR-612 had a significant inversed correlation with tumor size and stage, intrahepatic metastasis, and microvascular invasion in one cohort with 37 primary HCC tissues. And the patients with low expressed levels of miR-612 usually had a poor metastasis-free survival [19]. To confirm above observation, we enrolled another cohort with 134 primary HCC tissues, whose clinicopathological features are listed in details in Table 1. 
Table 1 Correlation between miR-612 expression and clinicopathologic in HCC patients

\begin{tabular}{|c|c|c|c|c|}
\hline \multirow[t]{2}{*}{ Characteristics } & \multirow{2}{*}{$\begin{array}{l}\text { Cases }(n= \\
134)\end{array}$} & \multicolumn{3}{|c|}{ Relative miR-612 expression } \\
\hline & & miR-612 low $(n=63)$ & miR-612 $2^{\text {high }}(n=71)$ & $p$-value ${ }^{a}$ \\
\hline Age (year) & & & & 0.284 \\
\hline$\leq 58$ & $70(52.2 \%)$ & 36 & 34 & \\
\hline$>58$ & $64(47.8 \%)$ & 27 & 37 & \\
\hline Sex & & & & 0.790 \\
\hline Male & $105(78.4 \%)$ & 50 & 55 & \\
\hline Female & $29(21.6 \%)$ & 13 & 16 & \\
\hline AFP (ng/ml) & & & & 0.136 \\
\hline$\leq 20$ & $58(43.3 \%)$ & 23 & 35 & \\
\hline$>20$ & $76(56.7 \%)$ & 40 & 36 & \\
\hline $\mathrm{ALT}(\mathrm{U} / \mathrm{L})$ & & & & 0.789 \\
\hline$\leq 75$ & $115(85.8 \%)$ & 55 & 60 & \\
\hline$>75$ & 19 (14.2\%) & 8 & 10 & \\
\hline $\mathrm{HBsAg}$ & & & & 0.101 \\
\hline Negative & $32(23.9 \%)$ & 11 & 21 & \\
\hline Positive & $102(76.1 \%)$ & 52 & 50 & \\
\hline HCVAb & & & & 0.320 \\
\hline Negative & $12(9.0 \%)$ & 4 & 8 & \\
\hline Positive & $122(91.0 \%)$ & 59 & 63 & \\
\hline Liver cirrhosis & & & & 0.647 \\
\hline No & $32(23.9 \%)$ & 13 & 17 & \\
\hline Yes & $101(75.4 \%)$ & 50 & 54 & \\
\hline NA & $1(0.7 \%)$ & & & \\
\hline Tumor size (cm) & & & & 0.002 \\
\hline$<3$ & $21(15.7 \%)$ & 5 & 16 & \\
\hline $3-5$ & 40 (29.9\%) & 14 & 26 & \\
\hline$>5$ & 73 (54.4\%) & 44 & 29 & \\
\hline NA & 0 & & & \\
\hline Tumor number & & & & 0.959 \\
\hline Single & 96 (71.6\%) & 45 & 51 & \\
\hline Multiple & 38 (28.4\%) & 18 & 20 & \\
\hline $\mathrm{BCLC}$ & & & & 0.045 \\
\hline A & $14(10.4 \%)$ & 3 & 11 & \\
\hline B & 71 (53.0\%) & 31 & 40 & \\
\hline C & 49 (36.6\%) & 29 & 20 & \\
\hline NA & 0 & & & \\
\hline Differentiation & & & & 0.032 \\
\hline । & $4(3.0 \%)$ & 1 & 3 & \\
\hline$\|$ & 89 (66.4\%) & 40 & 49 & \\
\hline III & $41(30.6 \%)$ & 22 & 19 & \\
\hline NA & 0 & & & \\
\hline Tumor thrombus & & & & 0.020 \\
\hline No & $82(61.2 \%)$ & 32 & 50 & \\
\hline Yes & 52 (38.8\%) & 31 & 21 & \\
\hline
\end{tabular}


Table 1 Correlation between miR-612 expression and clinicopathologic in HCC patients (Continued)

\begin{tabular}{llll}
\hline Characteristics & $\begin{array}{l}\text { Cases }(n= \\
\text { Relative miR-612 expression }\end{array}$ & miR-612 $^{\text {high }}(n=71)$ & \\
\hline NA & 0 & & \\
Ascites & & & \\
No & $1342^{\text {low }}(n=63)$ & 69 \\
Yes & $129(96.3 \%)$ & 60 & 2 \\
NA & $5(3.7 \%)$ & 3 & \\
\hline
\end{tabular}

Bold data indicates statistical significance $(p<0.05)$

${ }^{\text {a }}$ Qualitative variables were compared using $x^{2}$-test

Using fluorescence in situ hybridization, miR-612 was showed expressed both in cytoplasm and nuclei (Fig. 1a). The average density of miR-612 in cancerous tissues was significantly lower than these of paired adjacent nonHCC tissues $(0.415 \pm 0.010$ vs. $0.702 \pm 0.008, p<0.001$; Fig. 1b). When cutting off with median value of integrated optical density (mIOD), 63 of 134 patients (47\%) were categorized into miR-612 low-expressed group $\left(\mathrm{miR}-612^{\mathrm{low}}\right)$ and the remaining $(71 / 134,53 \%)$ into miR612 high-expressed group (miR-612 $2^{\text {high }}$ ).

As shown in Table 1, miR-612 is negatively related with BCLC staging $(p=0.045)$, differentiation $(p=0.032)$, tumor size $(p=0.002)$, and tumor thrombus $(p=0.02)$ of HCC. Kaplan-Meier analysis showed that the low expressed levels of miR-612 were correlated with poor progress-free survival (PFS) $(p=0.001)$ and poor overall survival (OS) ( $p=0.007$; Fig. 1c, d), which was consistent with our previous results. Taken together, these clinical data reveal once more that low level of miR-612 is a poor prognostic predictor of HCC patients after surgical resection.

\section{HADHA is a direct target of miR-612}

Loss- and gain-of-function studies showed that akt2 and sp1 are the two direct targets of miR-612 which negatively regulated cancerous metastasis and the stemness of HCC [19, 24]. As a given miRNA usually regulate multiple targets and signaling pathways simultaneously, miR-612-hybridized RNAs were pulled down and sequenced by RNA immunoprecipitation and RNA-seq assays respectively for a comprehensive targets picture of miR-612. After kicked off unknown genes, 1747 upexpressed genes and 2316 down-expressed genes were filtrated in miR-612-mimic transfected cells when compared with their negative counterpart (Fig. 1e). The gene ontology of these differentially miR-612-binding targets in biological process, cellular component, and molecular function was showed in Additional file 1: Figure S1D-F. In all down-expressed genes, 948 were identified twice by RNA-seq analyses (Fig. 1f), and their biological functions focus on the processes of endoplasmic reticulum, ECM-receptor interaction, RNA transport, actin cytoskeleton remodeling, as well as metabolism reprogramming according to Kyoto encyclopedia of genes and genomes (KEGG) analysis (Fig. 1g). More interestingly, hadha (KEGG: K07515), one pivotal center of miR-612 predicted network in our previous study, was repeatedly pulled-down, indicating the involvement of miR-612 in lipid metabolism (Fig. 1h). To test whether hadha is a direct target of miR-612, a wild-type (plasmids named H2294) and mutant (plasmids named H2336) of hadha at seed sequence in a 3 '-UTR element were cloned into a dual luciferase reporter (Fig. 1i), and then transiently transfected into $293 \mathrm{~T}$ cells. Indeed, the levels of luciferase activities have been reduced nearly by $50 \%$ in cells transfected with wild-type 3 '-UTR element of hadha when compared with cells with control vector $(p<0.001$; Fig. 1j). In conclusion, hadha is the direct target gene of miR-612.

\section{MiR-612 suppresses HCC invasion and migration by targeting $H A D H A$}

Although the inhibitory effects of miR-612 on HCC invasion and metastasis had been established [19], its underlying mechanisms was far from elucidated. In the study, we focus our attention on hadha in mediating the biological functions of miR-612. Therefore, loss- and gain-of-functions of miR-612 or hadha were investigated using a lentivirus infected strategy (Additional file 2: Figure S2A-C, miR-612-overexpression and -knockdown virus or respective mock were suppled by Hanyin Biotechnology Limited Company, Shanghai; the series virus of HADHA or negative control were ordered in Genechem Co., LTD, Shanghai). Remarkably morphological changes of HCCLM3 and HepG2 were noted after gainor loss-of-function of miR-612 or hadha. First of all, HepG2 $2^{\text {miR-612-KD }}$ or HepG2 $2^{\text {hadha-OE }}$ cells appeared to grow in scattering spindle morphology rather than in ovoid cluster in NC cells in optical microscope (Fig. 2a). While the opposite morphological changes were observed in HCCLM3 $3^{\text {miR-612-OE }}$ or HCCLM3 ${ }^{\text {hadha-KD }}$ cells which tended to grew into pebble-shape (Fig. 2b). Indeed, more fusiform shapes with slender pseudopodia could be viewed in HepG2 $2^{\text {miR-612-KD }}$ or HepG2 $2^{\text {hadha-OE }}$ 
A

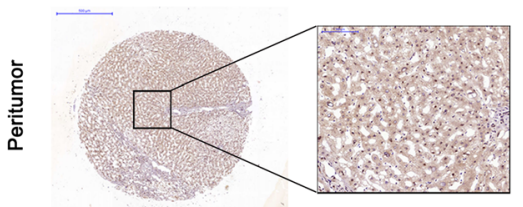

B

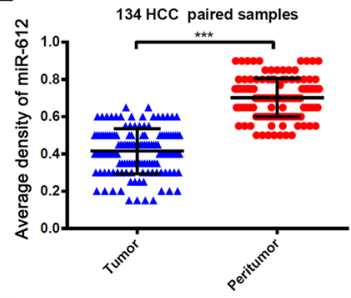

E

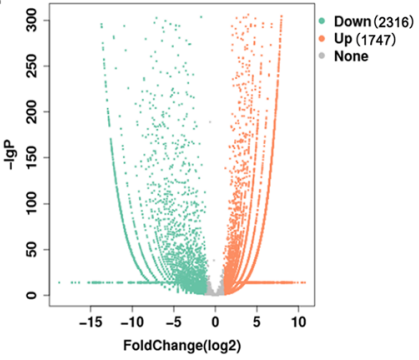

H

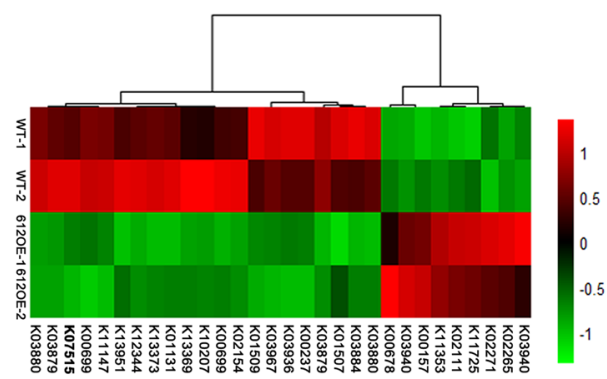

miR-612

C

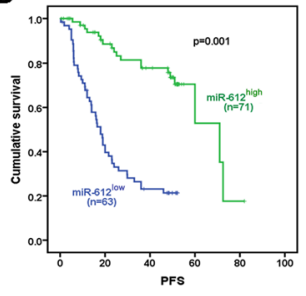

F

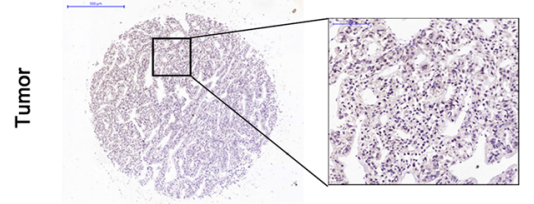

D

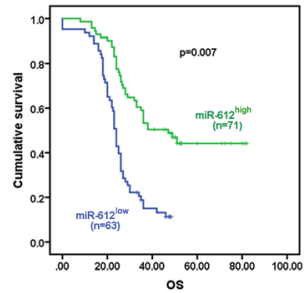

$\mathbf{G}$
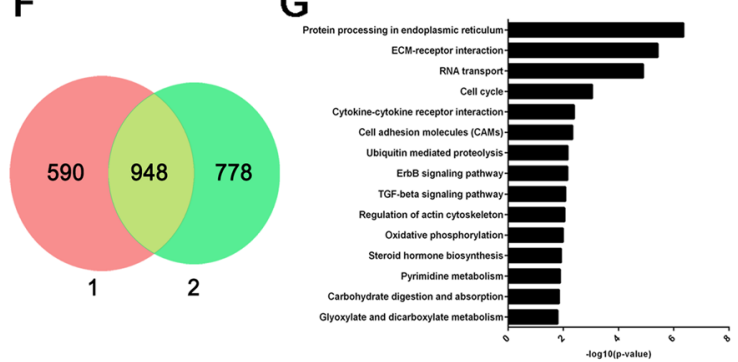

J

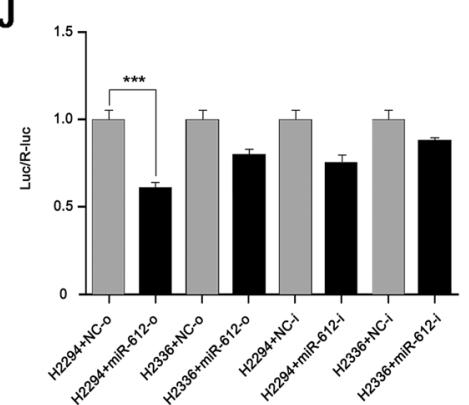

I

$\begin{array}{rcc}\text { HADHA 3'UTR } & 5 & \text {...UCUGUGCAGAUGCUUUGCCCAGG... } \\ & & \|\||||||||| \mid \\ \text { hsa-miR-612 } & 3 & \text { UUCCUCGAGUCUUCGGGACGGGUCG } \\ \text { mutant 3'UTR } & 5, & \text {...UCUGUGCAGAUGCUUGAGGATAG... }\end{array}$

Fig. 1 MiR-612 and hadha, its new target, in HCC. a, b Representative images with high and low expressed level of miR-612 in HCC and their paired adjacent tissues in immunohistochemistry. Bars: (left) magnification $\times 100$, (right) magnification $\times 400$. c, d Kaplan-Meier analysis of PFS and OS in HCC patients using SPSS 22.0. e Volcano map of the differential expressed genes (Ordinate: statistical significance of changes in expression; abscissa: multiple changes in the differential genes. Orange represents upregulated genes and downregulated ones in green). $\mathbf{f}$ Repeated downregulated genes in two independent RNA-seqs. g KEGG pathway analysis (Ordinate: the KEGG signal path; abscissa: $p$ value). $\mathbf{h}$ Gene profiles related to lipid metabolism, including hadha. i Schematic diagram of the dual luciferase reporter vector of miRNA target. $\mathbf{j}$ Luciferase activity in 293T cells. H2294:pMIR-REPORT hadha WT 3'-UTR; H2336:pMIR-REPORT hadha mut 3'-UTR. Statistical analysis by Student's $t$ test. $\left.{ }^{* * *} p<0.001\right)$. Data are mean \pm SEM of three independent experiments

cells using scanning electron microscope than these of HepG2 ${ }^{\text {NC }}$ cells (Fig. 2c), while more pseudopodia could be found at the edge of HCCLM3 ${ }^{\mathrm{NC}}$ cells than these of HCCLM3 $3^{\text {miR-612-OE }}$ or HCCLM3 $3^{\text {hadha-KD }}$ cells (Fig. 2d). These results showed clearly that miR-612 and hadha regulated HCC cell morphology oppositely.
Next, we wondered whether hadha would promote cell migration and invasion of HCC, the key steps in tumor metastatic cascade, opposite to miR-612. Again, the scratched spaces reduced no difference at $24 \mathrm{~h}$, but up to $30.5 \%$ at $48 \mathrm{~h}$ in HepG2 ${ }^{\text {miR-612-KD }}(p=0.018$; Fig. 2e, g) and no difference at $24 \mathrm{~h}$, up to $50 \%$ at $48 \mathrm{~h}$ 


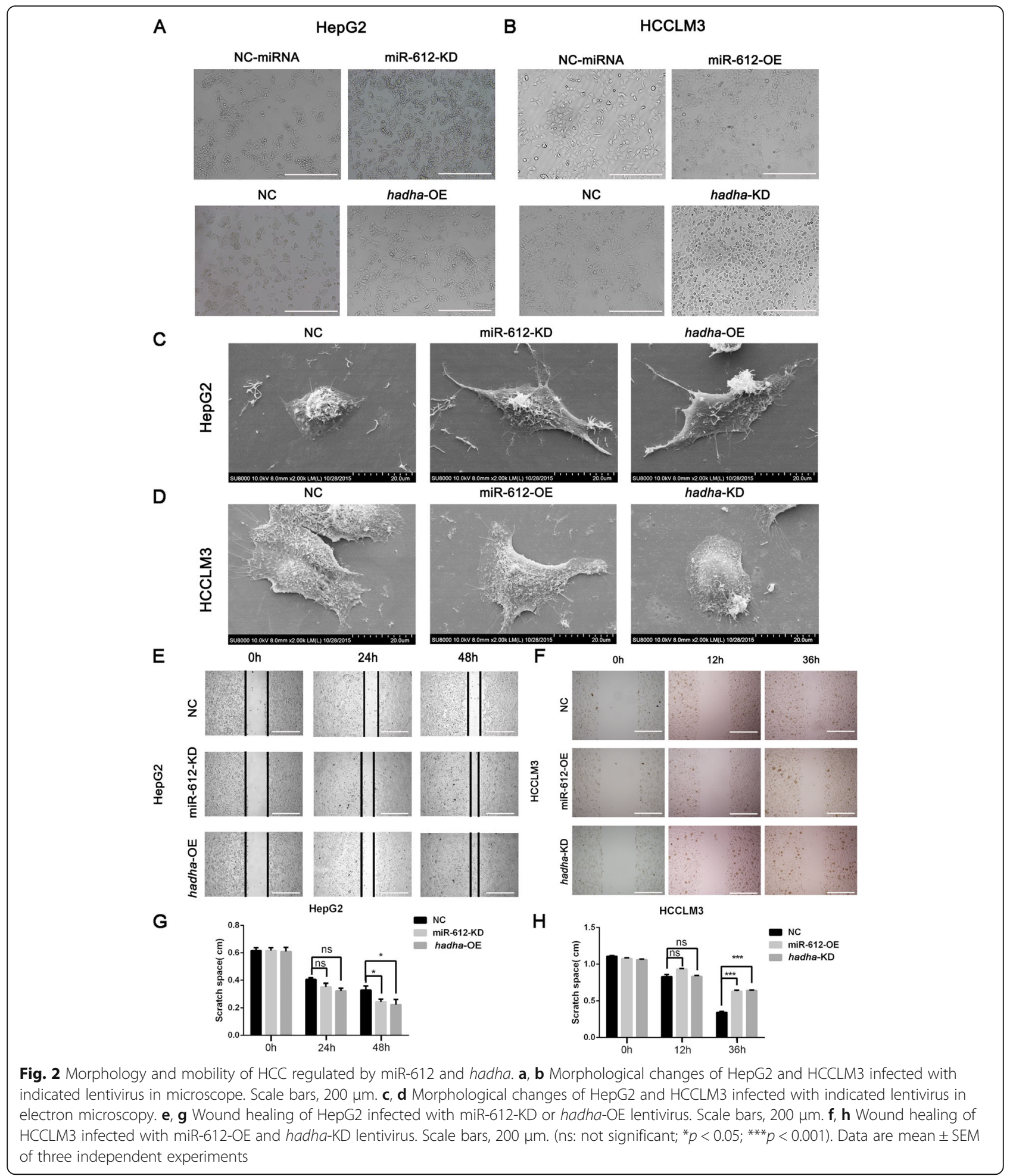

in HepG2 $2^{\text {hadha-OE }}$ respectively ( $p=0.021$; Fig. $2 \mathrm{e}, \mathrm{g}$ ). While the wounded spaces were not significant at $12 \mathrm{~h}$, and increased nearly by $50 \%$ at $36 \mathrm{~h}$ both in HCCLM $^{\text {miR-612-OE }} \quad(p<0.001 ; \quad$ Fig. $2 f, \quad$ h $)$ or HCCLM $3^{\text {hadha-KD }}$ cells $(p<0.001$; Fig. 2 f, h), compared with their control counterparts. Similarly, the numbers of HepG2 $2^{\text {miR-612-KD }}$ or HCCLM3 ${ }^{\text {miR-612-OE }}$ cells in Transwell assays were about 3 - or 0.5 -fold as much as their control cells respectively $(p<0.05$; Fig. $3 \mathrm{a}, \mathrm{b})$. The numbers of HepG2 $2^{\text {hadha-OE }}$ or HCCLM3 ${ }^{\text {hadha-KD }}$ cells in 
A

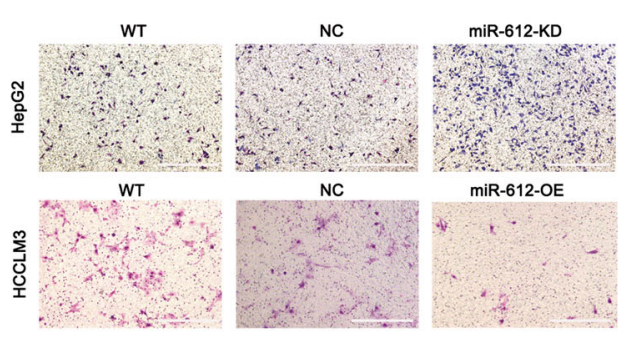

B

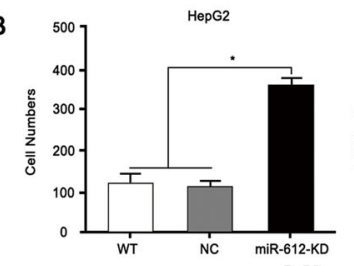

E

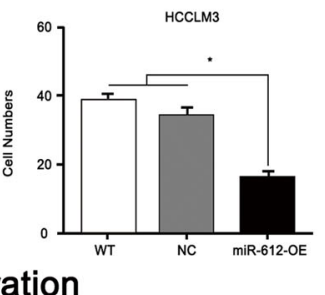

Migration

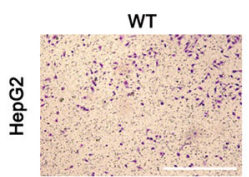

WT

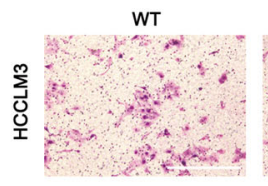

F

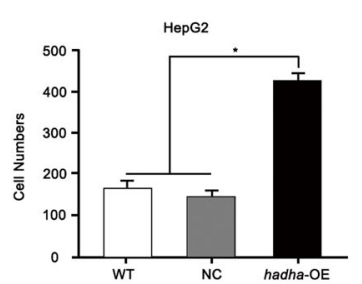

I
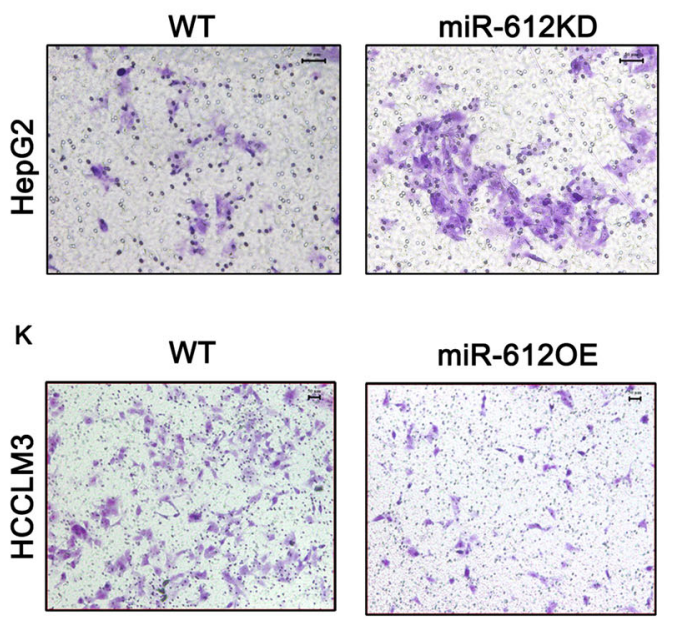

C

\section{Invasion}
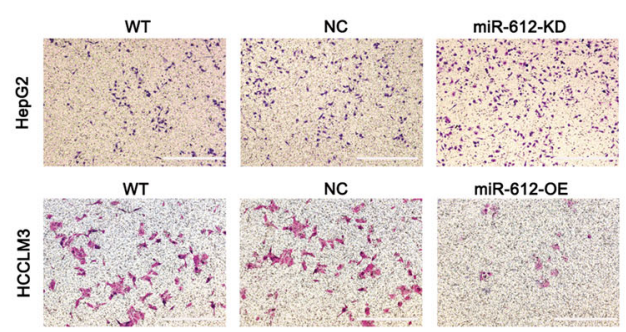

miR-612-OE

D
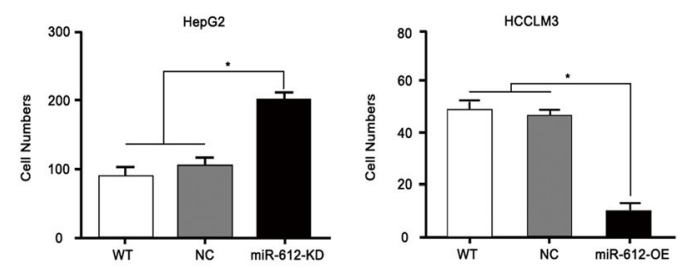

Invasion

G
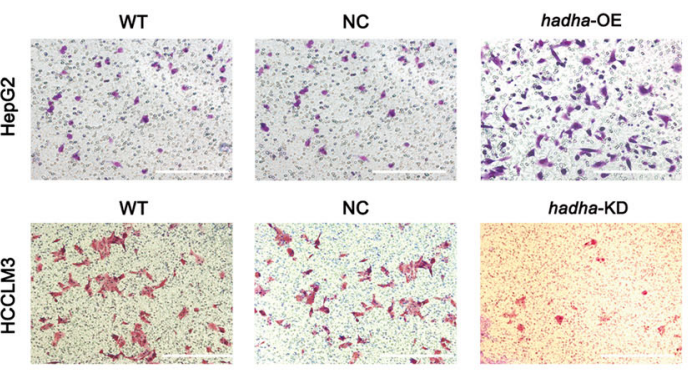

H
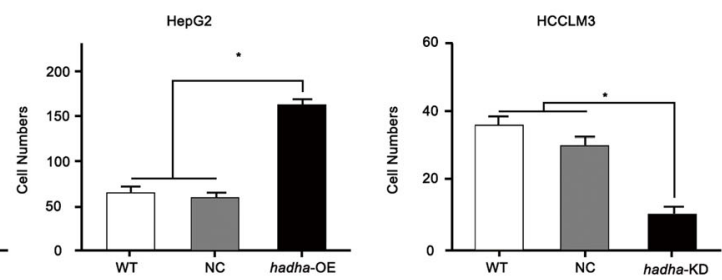

J
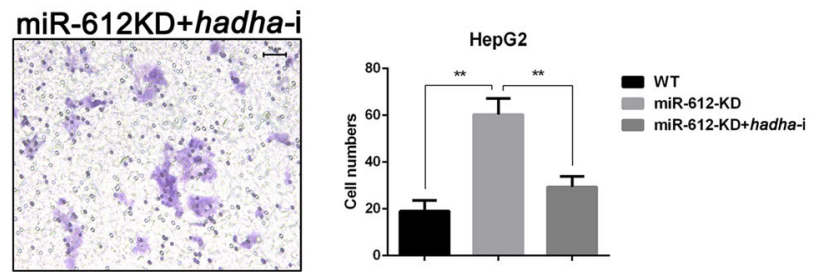

L

miR-6120E
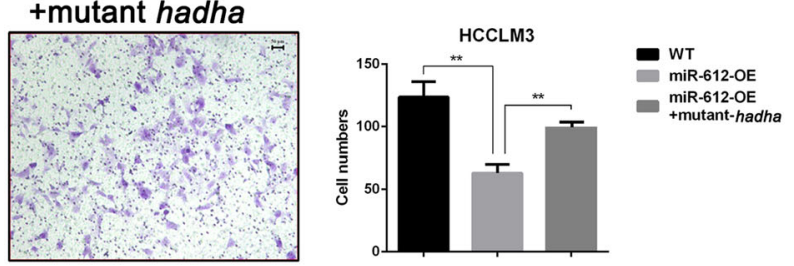

Fig. 3 (See legend on next page.) 
(See figure on previous page.)

Fig. 3 MiR-612 suppresses invasion and migration of HCC by targeting hadha. $\mathbf{a}$, b Cell migration abilities and statistic results of HepG2 ${ }^{\text {miR-612-KD }}$ and HCCLM3 $3^{\text {miR-612-OE }}$ cells. Scale bars, $200 \mu \mathrm{m}$. c, d Cell invasion abilities and statistic results of HepG $2^{\text {miR-612-KD }}$ and HCCLM3 ${ }^{\text {miR-612-OE }}$ cells. Scale bars, $200 \mu \mathrm{m}$. e, f Cell migration abilities and statistic results of HepG2 ${ }^{\text {hadha-OE }}$ and HCCLM3 ${ }^{\text {hadha-KD }}$ cells. Scale bars, $200 \mu \mathrm{m}$. $\mathbf{g}$, h Cell invasion abilities and statistic results of HepG2 $2^{\text {hadha-OE }}$ and HCCLM3 $3^{\text {hadha-KD }}$ cells. Cell migration abilities and statistic results of HepG $2^{\text {miR-612-KD }}$ cells after hadha was knocked down. Scale bars, $200 \mu \mathrm{m}$. i, j Cell migration abilities and statistic results of HCCLM3 miR-612-OE cells after HADHA was rescued. Scale bars, $50 \mu \mathrm{m} . \mathbf{k}$, I Cells $\left({ }^{*} p<0.05 ;{ }^{* *} p<0.01\right)$. Data are mean \pm SEM of three independent experiments. Scale bars, $50 \mu \mathrm{m}$

Transwell assays were increased or decreased by two times compared with their corresponding NC cells $(p<$ 0.05; Fig. 3e, f). Again, the numbers of successfully invaded HepG2 $2^{\text {miR-612-KD }}$ or HepG2 $2^{\text {hadha-OE }}$ cells were about 2- or 3-fold as much as nontreated (WT) and blank vector $(\mathrm{NC})$ infected cells $(p<0.05$; Fig. $3 \mathrm{c}-\mathrm{f})$. And the numbers of invaded HCCLM3 ${ }^{\text {miR-612-OE }}$ or HCCLM $3^{\text {hadha-KD }}$ cells were significantly reduced by more than 5- or 3-fold, respectively. ( $p<0.05$; Fig. 3c-f). The above results suggested that miR-612 inhibit cell migration and invasion of HCC probably by targeting hadha.

To further confirm the effects of HADHA in miR-612mediated cell mobility, HADHA levels were largely rescued in HCCLM3 ${ }^{\text {miR-612-OE }}$ cells after co-transfected with synonymous mutant of hadha, or inhibited by hadha-shRNA in HepG2 $2^{\text {miR-612-KD }}$ cells. Indeed, 2-fold enhanced invasive abilities of HepG2 ${ }^{\text {miR-612-KD }}$ cells were partially compromised after co-transfected with hadhashRNA ( $p<0.01$; Fig. 3i, j). Similarly, decreased invasive abilities of HCCLM $3^{\text {miR-612-OE }}$ cells were partially restored when co-transfected with synonymous mutant of hadha ( $p<0.01$; Fig. $3 \mathrm{k}, 1)$. All these findings demonstrated that miR-612 did inhibit cell migration and invasion partially mediated by HADHA.

\section{MiR-612 restrains invadopodia of HCC directly by HADHA and inhibit EMT via Wnt/ß-catenin signaling}

Our morphological observations of electron microscopy suggested that invadopodia may be involved in miR-612 regulation on HCC metastatic potential. Naturally, Cortactin and Caveolin-1, two vital proteins of invadopodia, were selected to analyze their conversion after miR-612 or hadha manipulation by laser confocal microscopy [34, 35]. Cortactin (red staining), F-actin (green staining) (Fig. 4a, b), and Caveolin-1 (red staining) (Fig. 4c, d) were expressed much sharper in HCCLM3 ${ }^{\mathrm{NC}}$ cell with lower endogenous levels of miR-612 than these in HepG2 ${ }^{\text {NC }}$ cell. However, Cortactin, F-actin, and Caveolin-1 were enhanced robustly both in HepG2miR-612-i cells and HepG2 $2^{\text {hadha-o }}$ cells compared to HepG2 ${ }^{\mathrm{NC}}$ cells, and these proteins, especially Cortactin, were gathered at the edge of the cells (Fig. 4a, c). While, all these proteins were significantly weakened in HCCLM $3^{\text {miR-612-o }}$ and HCCLM3 ${ }^{\text {hadha-i }}$ cells (Fig. 4b, d), which were correlated to their decreased abilities of cell migration and invasiveness previously. These results showed intuitively that miR-612 and HADHA could remodel F-actin cytoskeleton and invadopodia formation of HCC via dynamic conversations of Cortactin and Caveolin-1.

Invadopodia is usually resorted to degrade the surrounding matrix and promote a distant invasion of cancerous cell. Therefore, the impacts of miR-612 and hadha on functional invadopodia were further tested by gelatin degradation assay using HCCLM3, HCC cell line with high metastatic potential. The function of invadopodia was judged by the co-localizations of matrix degradation, F-actin puncta, and Cortactin foci according to the manufacturer's instructions, as shown in the white rectangles in $\mathrm{HCCLM}^{\mathrm{NC}}$ cells (Fig. 4e, f). Only a small amount of Cortactin and F-actin could be observed without obvious gelatin degradation, indicating that they were in a non-functional status of invadopodia in $\mathrm{HCCLM}^{\text {miR-612-OE }}$ and HCCLM3 $3^{\text {hadha-KD }}$ cells (Additional file 2: Figure S2D, E). The above results clearly showed that the inhibitory effects of miR-612 and the promoting effects of hadha were exhibited corresponding to the numbers of functional invadopodia.

To further clarify regulatory proteins of invadopodia after miR-612 or hadha manipulation, a series of proteins whose expressed levels were detected by Western blottings. And Cortactin and Caveolin-1 were once again low expressed in HepG2 $2^{\mathrm{NC}}$ cells and high expressed in $\mathrm{HCCLM} 3^{\mathrm{NC}}$ cells. Both proteins were dramatically increased in HepG2 $2^{\text {miR-612-KD }}$ or HepG2 $2^{\text {hadha-OE }}$ cells and markedly decreased in HCCLM3 ${ }^{\text {miR-612-OE }}$ or HCCLM $3^{\text {hadha-KD }}$ cells, which was consistent with the numbers of functional invadopodia and the migration abilities of cancerous cells.

In order to explore whether miR612/HADHA would suppress the invadopodia formation and subsequently rearrange the MMPs and reduce other adhesion molecules accumulation thereby inhibit epithelial to mesothelial transformation (EMT), we detected miR-612 and hadha manipulation expression change on EMTassociated signal molecules. E-cadherin, an epithelial phenotype protein, and $\beta$-catenin, a mesothelial phenotype protein, were significantly down- and upregulated respectively in HepG2 $2^{\text {miR-612-KD }}$ or HepG2 $2^{\text {hadha-OE }}$ cells. Meantime, knockdown of miR-612 or overexpression of hadha in HepG2 induced an augment in the protein 

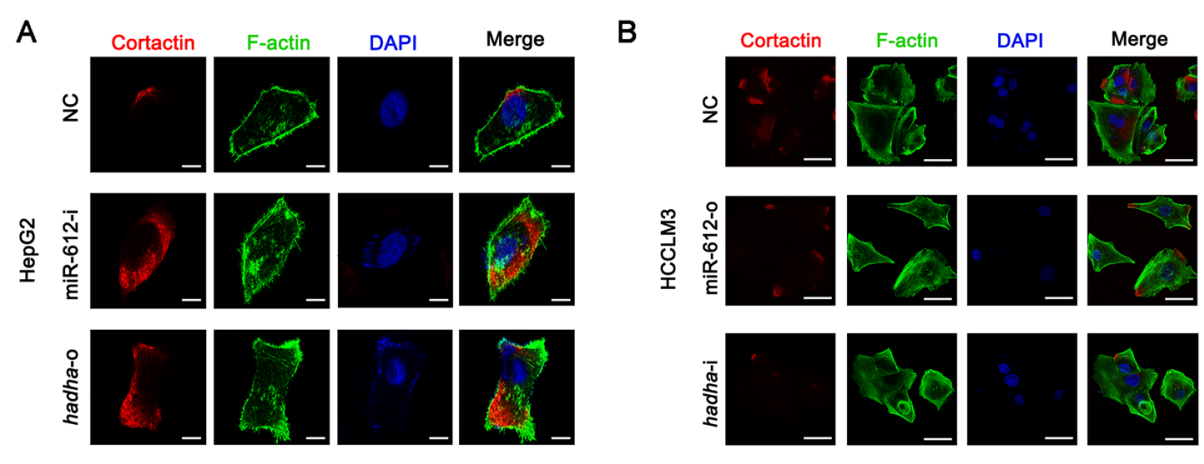

C

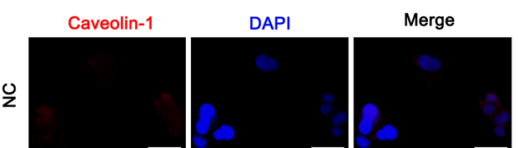

D
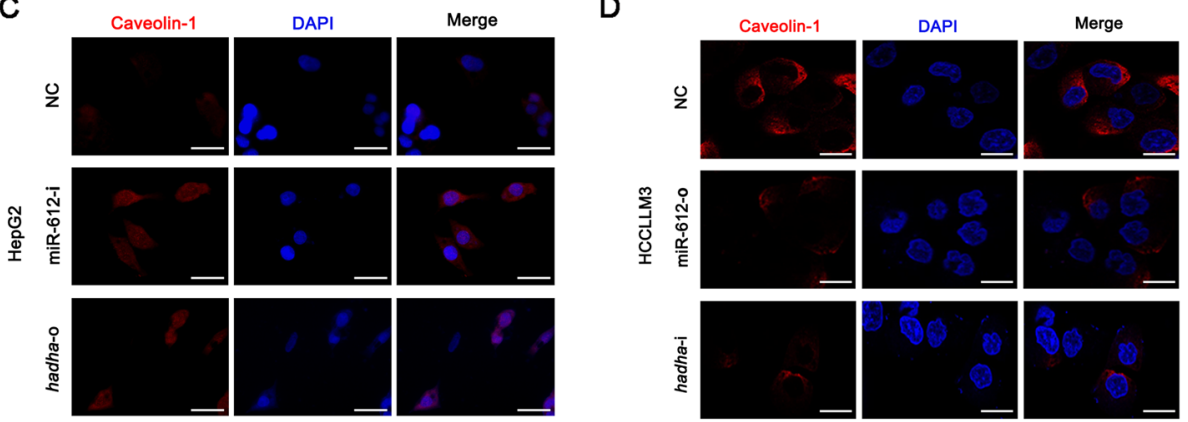

E

HCCLM3 NC

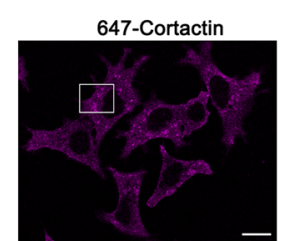

FITC-Phalloidin

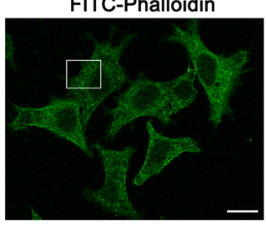

Cy3-Gelatin

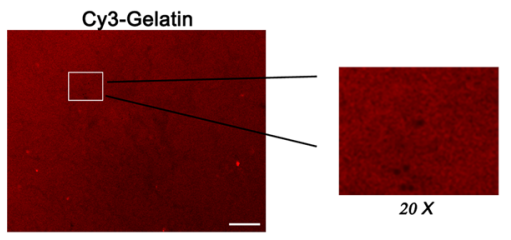

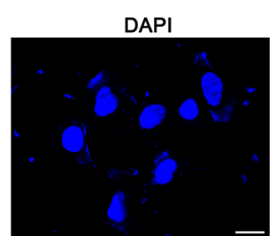

Merge

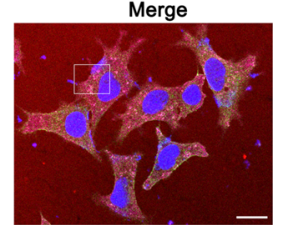

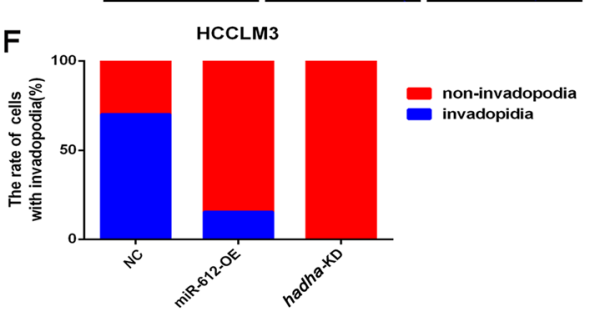

G
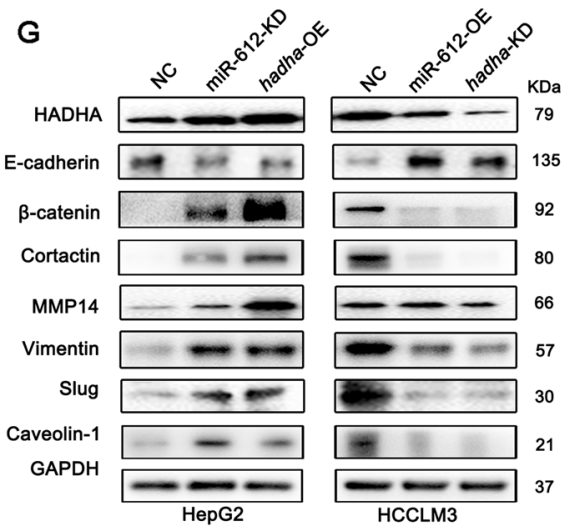

Fig. 4 MiR-612 restrains HCC invadopodia by HADHA. a, c Expression of invasive pseudopodia-related proteins, Cortactin, F-actin, and Caveolin-1, in HepG2 cells with indicated treatments. a Scale bars, $5 \mu \mathrm{m}$. c Scale bars, $30 \mu \mathrm{m}$ (b, d) Expression of invasive pseudopodia-related proteins, Cortactin, F-actin and Caveolin-1, in HCCLM3 cells with indicated treatments. b Scale bars, 50 um. d Scale bars, $15 \mu \mathrm{m}$. e, f The number and statistic results of invasive pseudopods of HCCLM3 cells. Scale bars, 15 mm. g EMT and invadopodia biomarkers in HepG2 and HCCLM3 cells with indicated treatments analyzed by Western blots

expression of Vimentin, Slug and MMP14. The opposite trends were observed in HCCLM3 $3^{\text {miR-612-OE }}$ or HCCLM3 $3^{\text {hadha-KD }}$ cells. (Fig. 4g). These results indicated that HADHA promoted the formation of functional invadopodia against miR-612, accompanied by the EMT of HCC through Wnt/ $\beta$-catenin signaling pathway [19].
The formation of invadopodia and occurrence of EMT jointly promote HCC cell metastasis and invasion.

\section{HADHA promotes HCC metastasis in vivo}

In our previous study, miR-612 had been verified to suppress the invasive-metastatic cascade in $\mathrm{HCC}$ in vitro and 
in vivo [19]. Here, the roles of HADHA on in-vivo tumor growth and metastasis were surveyed using micro-spiral CT scanning in the orthotopic HCCLM3 xenograft models (Additional file 3: Figure S3A, B). After 8 weeks, we observed that two mice in HCCLM ${ }^{\mathrm{NC}}$ group $(2 / 6$, one died of ascites) developed pulmonary metastasis foci compared with none of HCCLM3 ${ }^{\text {hadha-KD }}$ group (0/6) (Fig. 5a). After sacrificed, obviously smaller tumor volumes and less intraliver metastasis foci were found in $\mathrm{HCCLM}^{\text {hadha-KD }}$ xenografts than in $\mathrm{HCCLM}^{\mathrm{NC}}$ xenografts (Additional file 3: Figure S3C). The numbers of metastatic foci in lung and liver of HCCLM $3^{\text {hadha-KD }}$ recipient mice were dramatically lower than that of $\mathrm{HCCLM}^{\mathrm{NC}}$ in HE staining $(p<0.01, p<0.05$; Fig. 5b-e). Meanwhile, Cortactin, mainly located in cytoplasm, was significantly downregulated in paraffin-embedded HCCLM $3^{\text {hadha-KD }}$ xenograft tissues. And Caveolin-1, mainly expressed on membrane, was also remarkably decreased in paraffin-embedded HCCLM $3^{\text {hadha-KD }}$ xenograft tissues using immunological histological chemistry (IHC) staining (Fig. 5f, g). These observations demonstrated that HADHA itself indeed promoted the formation of invadopodia in vivo, resulting in an accelerated distant metastasis in HCC xenograft models.

\section{HADHA promotes $\beta$-oxidation of fatty acids in HCC}

To meet aggressive tumor growth, cancerous cells usually resort to seeking other resources, such as fatty acids, for material and energy supply apart from glycolysis even in normoxia. HADHA catalyzes the last three steps of mitochondrial $\beta$-oxidation of long chain fatty acids [36]. Here, we wondered whether or not HADHA regulated HCC invasion and metastasis by lipid reprogramming. Using bioenergetic energy analyzer, the activity of $\beta$-oxidation of fatty acids can be perfectly gauged by oxygen consumption rate (OCR). As etomoxir (ETO) is a specific inhibitor of $\beta$-oxidation by blocking the activity of carnitine palmitoyl transferase (CPT-1), it was chosen as a positive control in the study [37]. Indeed, the OCR of $100 \mu \mathrm{M}$ ETO-treated HepG2 and HCCLM3 cells were both decreased nearly by $50 \%$ when compared to their corresponding untreated cells (Fig. 6a, b). The maximum OCR of HepG2 $2^{\text {miR-612-KD }}$ and HepG2 $2^{\text {hadha-OE }}$ cells increased slightly, but no significant difference from HepG2 ${ }^{\mathrm{WT}}$ and HepG2 ${ }^{\mathrm{NC}}$ cells $(p>0.05$; Fig. $6 \mathrm{a})$. In contrast, the OCR of HCCLM3 $3^{\text {miR-612-OE }}$ and HCCLM $3^{\text {had }}$

${ }^{h a}$-KD cells were decreased obviously. Compared with the levels of $\mathrm{HCCLM}^{\mathrm{WT}}$ and $\mathrm{HCCLM} 3^{\mathrm{NC}}$ cells, the maximum OCR has reduced by $40 \%$ in $\mathrm{HCCLM}^{\mathrm{miR}-612-\mathrm{OE}}$ and by $60 \%$ in $\mathrm{HCCLM}^{\text {hadha-KD }}$ $(p<0.05$; Fig. 6b). All these results suggested that miR612 could inhibit $\beta$-oxidation of fatty acids by downregulating the expression of HADHA in HCC, especially in HCCLM3 cell.
To verify the role of HADHA-mediated $\beta$-oxidation on invadopodia and HCC metastasis, the levels of Cortactin were blotted after treated with $100 \mu \mathrm{M}$ ETO [37] and $100 \mathrm{mM}$ linoleic acid, a $\beta$-oxidation agonist. Unsurprisingly, the level of Cortactin was significantly upregulated in linoleic acid-treated HCCLM3 cells and downregulated in ETO-treated cells (Fig. 6c). And Cortactin was reduced remarkably in HCCLM3 ${ }^{\text {hadha-i }}$. Correspondingly, the levels of Cortactin were significantly increased both in HCCLM3 $3^{\text {miR-612-i }}$ and HCCLM $3^{\text {had- }}$ ${ }^{h a}-\mathrm{o}$. These results indicated that the increased activity of HADHA-mediated $\beta$-oxidation did promote the formation of invadopodia in HCC cells.

To evaluate the effects of miR-612 and HADAH on acetyl-CoA and ATP syntheses, acetyl-coenzyme assay kit was applied according to the manufacture's protocol. The standard line of acetyl CoA was established before sample fluorometric detection in Additional file 3: Figure S3D. The acetyl-CoA level of HCCLM3 ${ }^{\text {miR-612-o }}$ cells was decreased by $1 / 3$ of HCCLM3 ${ }^{\mathrm{NC}}$ cells, but no statistical significance between them $(p>0.05)$. More than $50 \%$ reduction of acetyl-CoA level was observed in HCCLM3 ${ }^{\text {hadha-i }}$ cells $(p<0.05$; Fig. 6d). Although opposite effects were achieved, no significant increased level of acetyl-CoA was observed both in HepG2 $2^{\text {miR-612-i }}$ or Hep$\mathrm{G} 2^{\text {hadha-o }}$ cells (data not shown). Meanwhile, the level of ATP had been increased by $53 \%$ in HepG2 $2^{\text {miR-612-KD }}$ $(p>0.05)$ and by $71 \%$ in HepG $2^{\text {hadha-OE }}$ cells $(p<0.01$; Fig. $6 \mathrm{~h})$, but reduced to $1 / 2$ and $1 / 4$ in $\mathrm{HCCLM}^{\text {miR-612-OE }}(p<0.05)$ and HCCLM $3^{\text {hadha-KD }}$ cells respectively $(p<0.01$; Fig. $6 \mathrm{~h})$. These results revealed that less level of acetyl-CoA and ATP was available for HCC growth and metastasis when $\beta$-oxidation inhibited by miR-612. However, the process could be largely reversed after the rescued expression of HADHA.

\section{HADHA-mediated cholesterol alteration directly affect cell membrane fluidity of invadopodia}

It is well known that acetyl-CoA and ATP can be used for biosynthesis of cholesterol, which is an essential component to maintain membrane integrity and fluidity of animal cells, especially of invaginated caveolae [38, 39]. Membrane lipid rafts construction, especially reprograming of cholesterol metabolism, will influence the invadopodia formation and its function, subsequently affecting tumor cell metastasis. To investigate the role of HADHA on cholesterol biosynthesis in HCC cells, $1 \mathrm{mM}$ methyl beta cyclodextrin $(\mathrm{M} \beta \mathrm{CD})$ was recruited to remove the cholesterol from plasma membrane [40]. With cholesterol assay kit, the endogenous cholesterol level of HepG2 was found to be much lower than that of HCCLM3 (Fig. 6e). And the levels of cholesterol were reduced by nearly $1 / 3$ in $\mathrm{HCCLM}^{\mathrm{miR}-612-\mathrm{OE}}(p<0.01)$ 


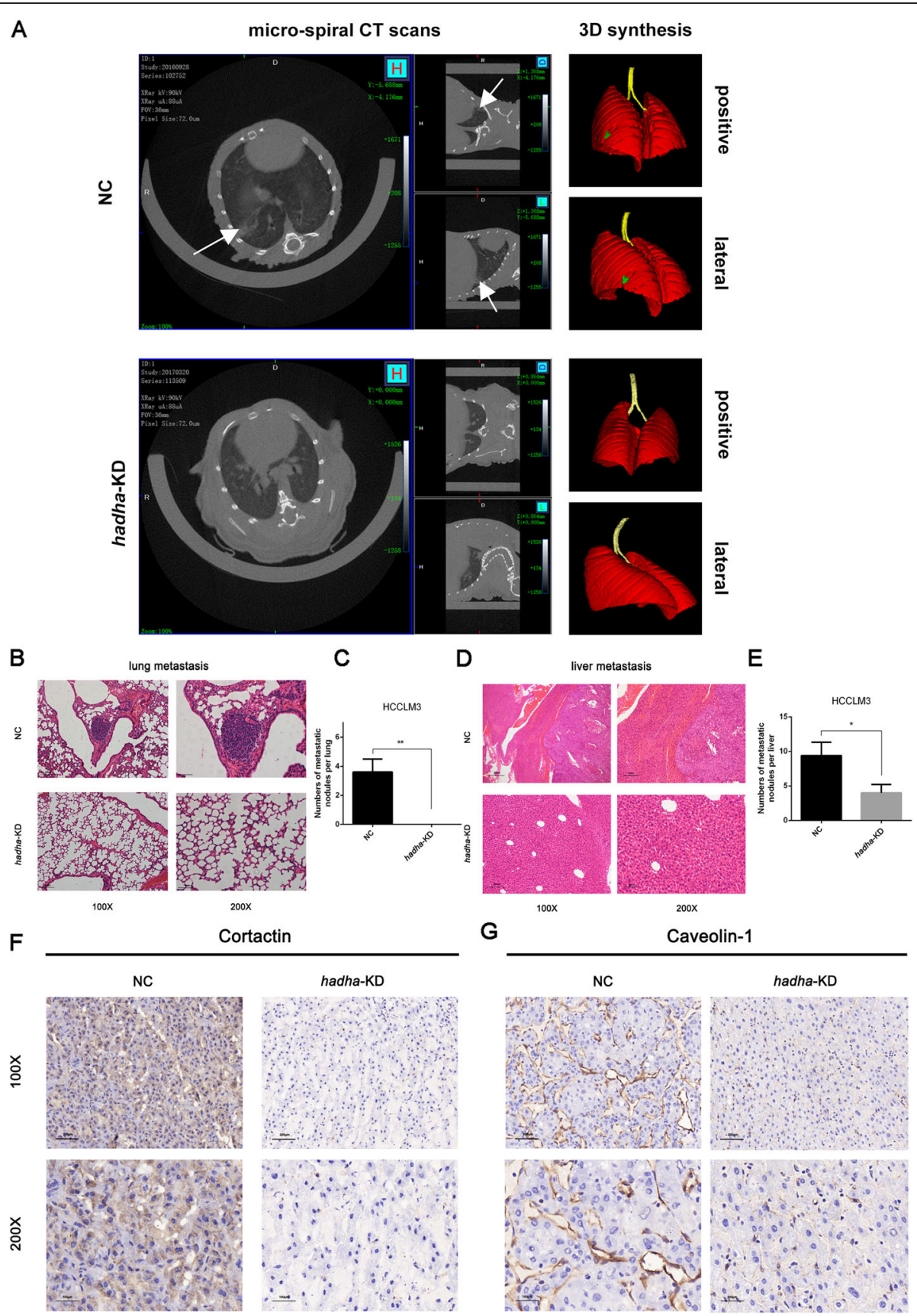

Fig. 5 HADHA promotes metastasis of HCC in vivo. a Metastatic foci in lung were imaged by micro-spiral CT scans using 3D synthesis. b, c Metastatic foci in lung and their statistic results of indicated HCCLM3 orthotopic xenografts (HCCLM $3^{\text {hadha-KD }}$ or HCCLM $3^{\mathrm{NC}}$ ) in $\mathrm{H}-\mathrm{E}$ staining. $\mathbf{d}$, e Metastatic foci in liver and their statistic results of indicated HCCLM3 orthotopic xenografts in H-E staining. Bars: (left) magnification $\times 100$, scale bars, $200 \mu \mathrm{m}$. (right) magnification $\times 200$, scale bars, $100 \mu \mathrm{m}$. f, g The levels of Cortactin and Caveolin-1 in liver orthotopic xenografts using IHC analyses. Bars: (up) magnification $\times 100$, scale bars, $200 \mu \mathrm{m}$. (down) magnification $\times 200$. scale bars, $100 \mu \mathrm{m}$. $\left({ }^{*} p<0.05\right.$; ${ }^{* *} p<0.01$ )

and a half in HCCLM3 ${ }^{\text {hadha-KD }}$ cells $(p<0.01)$ when compared with $\mathrm{HCCLM} 3^{\mathrm{NC}}$ cells (Fig. 6e).

Simultaneously, both levels of Cortactin and Caveolin1 were decreased significantly accompanied with Ecadherin up-regulation (Fig. 6f) and cell morphology changed from a fusiform into a rounded shape in
MBCD-treated HCCLM3 (data not shown). The fluorescence polarization (FP) was increased by $37.5 \%$ in HCCLM3 $3^{\text {miR-612-o }}(p<0.05), 68.4 \%$ in HCCLM3 ${ }^{\text {hadha-I }}$ $(p<0.001)$ and decreased by more than $1 / 3$ in HepG2miR-612-i $(p<0.05), 2 / 3$ in HepG2 $2^{\text {hadha-o }}$ cells $(p<0.01$; Fig. 6g), indicating that cell membrane fluidity was 


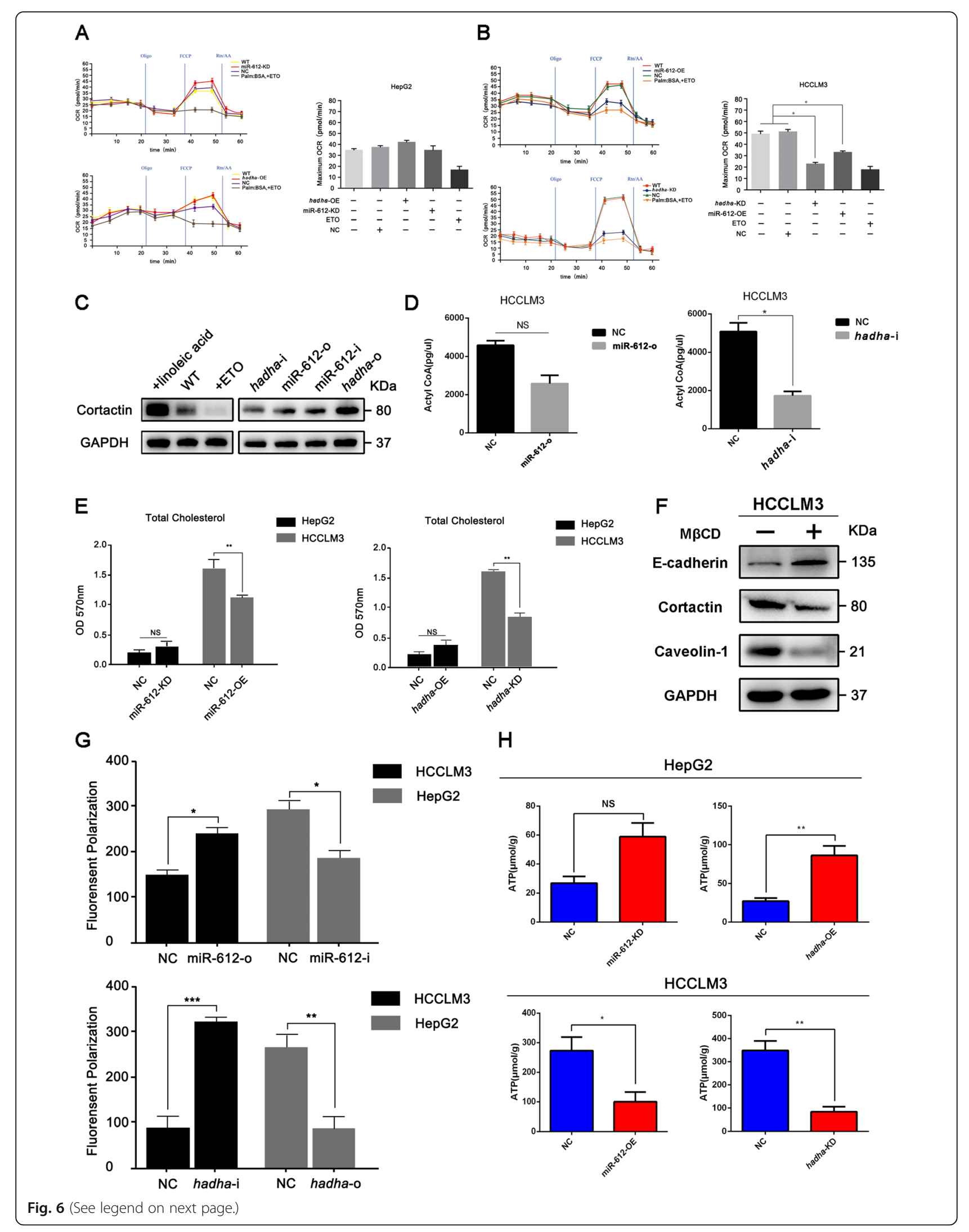




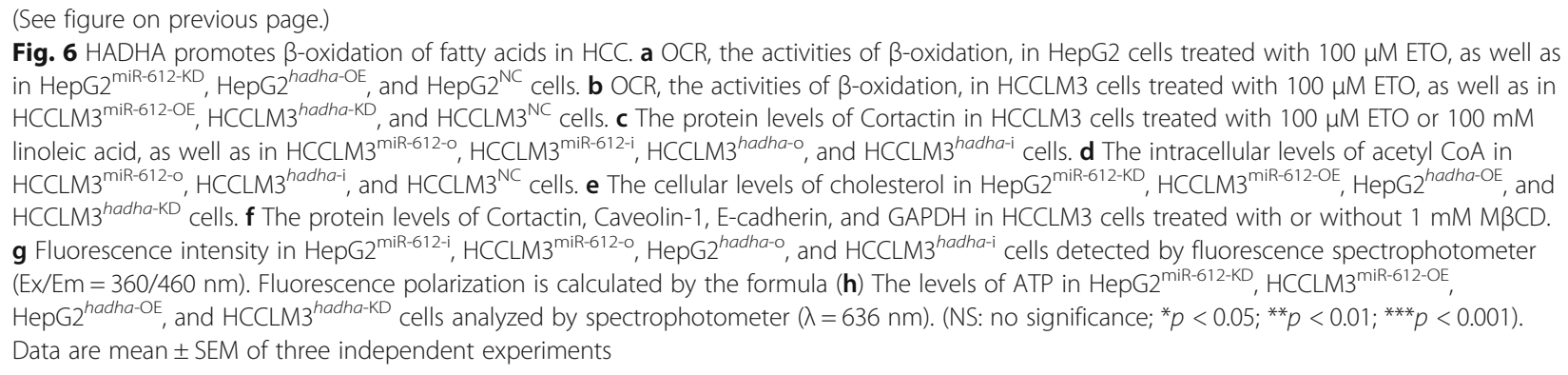

decreased by miR-612 and increased by HADHA. From the above results, we found that the levels of cholesterol oppositely regulated by miR-612 and HADHA, and decreased level of miR-612 could promote cholesterol biosynthesis and cell fluidity of HCC mediated by HADHA.

To further verify the HADHA-mediated HCC cell cholesterol content, we detected the lipid metabolites based on liquid chromatography mass spectrometry (LC-MS)/MS system. The results showed HepG2 hadha-OE had a high expression level of total cholesterol, especially 27-hydroxycholesterol, while HCCLM3 hadha-i presented a much lower expression (Fig. 7a).

SREBPs are transcription factors that are induced during cellular lipid deficit and that upregulate genes involved in cholesterol and fatty acid synthesis and trafficking. So we detected SREBP2 expression as well as its downstream targets to explore whether SREBP2/HMGCR cascade is the major regulator of cholesterol levels in HCC cells. The data showed that translocation of SREBP2 into the nucleus, and the ensuing transcription of sterol-responsive genes including HMGCR, 3-hydroxy-3-methylglutarylCoA synthase 1 (HMGCS1), mevalonate diphosphate decarboxylase (MVD), and SQLE, thereby facilitating the cholesterol synthesis and changing the invadopodia cell membrane fluidity (Fig. 7b).

\section{Clinical significance of HADHA in HCC patients}

To investigate the relationship of miR-612 and HADHA in HCC patients, total RNAs were first extracted from 15 HCC patients randomly and then the levels of miR-612 and hadha was analyzed by RT-PCR. There existed a significant negative correlation between miR-612 and hadha in HCC tissues, which was in line with previous observations ( $r=-0.5278, p=0.0432$; Fig. 7c). To investigate the clinical significance of HADHA in HCC patients, 134 tumor tissues and paired peritumor tissues were prepared for HADHA level analysis using IHC. HADHA, mainly located in cytoplasma, expressed prominently high in liver cancer tissues than in peritumors tissues $(p<0.001$; Fig. $7 d$, e). When cutting off with mIOD, 22.4\% (30/134) of HCC patients were sorted into HADHA low-expressed group $\left(\right.$ HADHA $\left.^{\text {low }}\right)$ and $77.6 \%(104 / 134)$ were into HADHA high-expressed group (HADHA $\left.{ }^{\text {high }}\right)$. Kaplan-Meier analysis showed that the high expressed levels of HADHA were correlated with poor OS $(p=0.003)$, and poor PFS $(p=0.001$; Fig. $7 \mathrm{f}, \mathrm{g})$. In short, HADHA was a poor prognostic indicator and a potential biomarker of relapse in HCC patients after surgical resection.

Above all, our study revealed that the miR-612 could suppress the invadopodia formation, EMT process, and metastasis through the HADHA/acetylCoA/HMGCoA/ cholesterol axis in HCCs (Fig. 7h).

\section{Discussion}

Invadopodia is a kind of pseudopodia, which is mainly responsible for extracellular matrix degradation, cell migration and invasion in local, extravasation of blood vessels, and dissemination into a distant organ in a spatial and temporal manner $[8,41]$. Therefore, a variety of components, such as Cortactin, Caveolin-1, Tks4/5, and protein tyrosine kinase $\mathrm{Src}$ of invadopodia, are usually used as indicators to gauge the mobility and invasion potentials of cancer cells in vitro and in vivo system [42, 43]. For example, Cortactin, a monomeric cytoplasmic protein, is able to be polymerized and rearranged in actin cytoskeleton of cell cortex after activated by external stimuli, thus promoting the formation of invadopodia, cell migration, and metastasis [44]. Caveolin-1, a scaffolding protein, can interact with Src tyrosine kinases, cholesterol, and TGF- $\beta$ receptor, etc., during the formation of invadopodia [34, 35]. By now, invadopodia is regarded as a kind of microdomain on cell membranes which is rich of cholesterol. If the cholesterol was depleted, invadopodia formation and persistence could be impaired. On these microdomains, a lot of proteins such as Cortactin, Caveolin-1, Receptors, signaling adaptors, and trafficking proteins are assembled. And thus, depletion of cholesterol will impair the membrane fluidity and protein trafficking of invadopodia [35]. Therefore, Cortactin, Caveolin-1, and cholesterol were chosen as the surrogated parameters for evaluating the formation and the function of invadopodia in the study. As to the subtle relationship among the cholesterol, invadopodia, and EMT, our results should be original. MiR-612/HADHA/ cholesterol alteration will directly affect the lipid rafts construction, thereby influence the formation of 

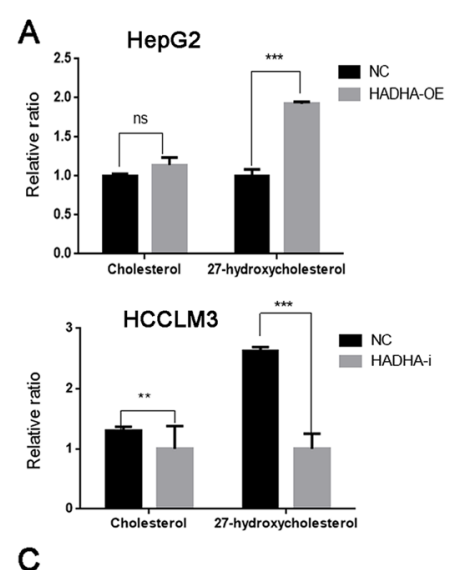

B

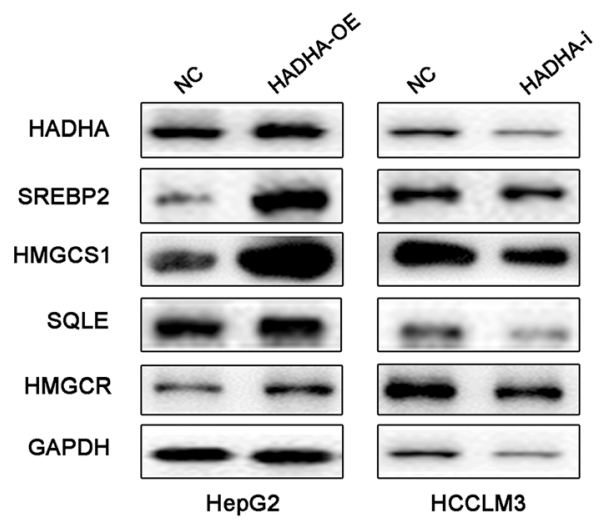

C

D
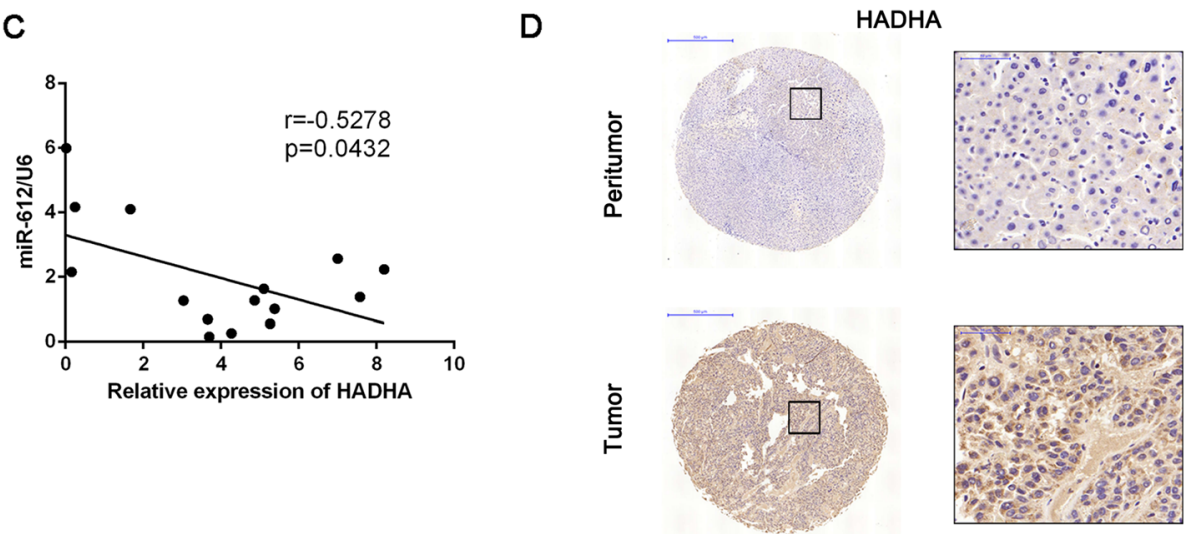

E

F
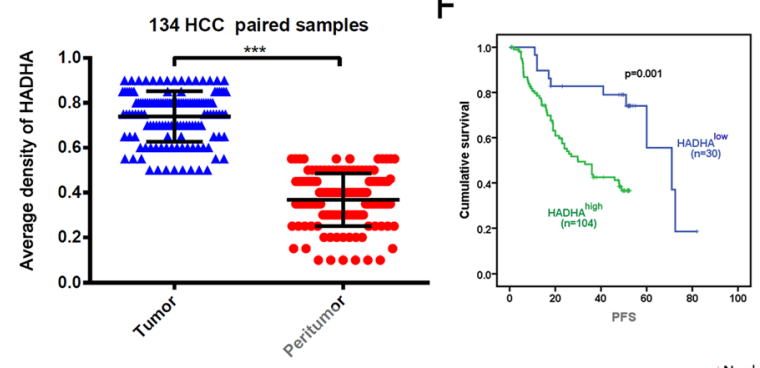

G

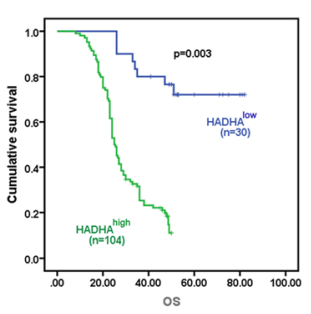

H

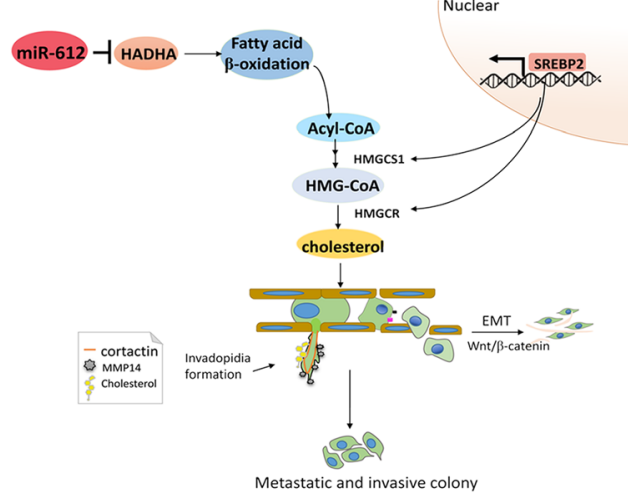

Fig. 7 (See legend on next page.) 
(See figure on previous page.)

Fig. 7 Clinical significance of HADHA in HCC patients. a The cholesterol and 27-hydroxycholesterol of HepG2 and HCCLM3 cells relative quantification based on liquid chromatography mass spectrometry (LC-MS)/MS system. (NS: no significance; ${ }^{* *} p<0.01 ;{ }^{* * *} p<0.001$ ). $\mathbf{b}$ Immunoblotting of proteins involved in cholesterol-biosynthesis pathway in HepG2 ${ }^{\text {hadha-OE }}$, HCCLM3 ${ }^{\text {hadha-KD }}$ cell, and their negative control cells. (Cells treated with negative control lentivirus). c Negative correlation between miR-612 and hadha mRNA in 15 HCC and their adjacent normal tissues. $\mathbf{d}$ Representative images of negative and positive HADHA staining in tumor and peritumor tissue from one HCC patient. Bars: (left) magnification $\times 100$, scale bars, $500 \mu \mathrm{m}$ (right) magnification $\times$ 400, scale bars, $50 \mu \mathrm{m}$. e The average densities of HADHA in 134 HCC and their paired normal tissues. $\mathbf{f}, \mathbf{g}$ Kaplan-Meier analyses of PFS and OS in HCC patients using SPSS 22.0. $\mathbf{h}$ Hypothesis diagram of lipid reprogramming in HCC cells modulated by miR-612/HADHA/cholesterol axis

invadopodia and invadopodia-mediated cellular matrix degradation, blunting EMT process of HCC. Furthermore, we discovered cholesterol metabolite, 27hydroxycholesterol level change was shocking in HADHA-treated HCC cells. As reported, it could not only regulate the target genes controlling cholesterol, glucose, and fatty acid metabolism of liver but also increase the proliferation of various cancer cell $[45,46]$.

It is well known that biological processes of cells are largely dependent on energy, saying ATP, which is usually derived from the metabolisms of carbohydrates, lipids, and amino acids. In normal, ATP is mainly derived from acetyl-CoA of aerobic oxidation of glucoses through tricarboxylic acid cycle. However, in tumor cells, glucoses are often catalyzed into pyruvate through hexokinase (HK) and phosphofructokinase (PFK) pathways for de novo biosyntheses of lipids and amino acids to meet their uncontrolled growth and metastasis, and only a small portion are reduced into lactic acids for ATP synthesis in mitochondria [3]. As a result, lipid metabolism reprogramming, such as $\beta$-oxidation of fatty acids in mitochondria, is initiated rapidly as a compensatory pathway in these hypermetabolic cancerous cells to fuel cell proliferation, invasion, and metastasis [47] and protect tumor cells from anoikis as well [48]. Meanwhile, acetyl-CoA, a vital intermediate of $\beta$-oxidation of fatty acids, can either be used to synthesize ATP, or cholesterol, or so on, in mammal cells.

Although the dynamics of protein components, interactions, modifications, signaling, and functions during cytoskeletal remodeling in the processes of invadopodia have been extensively studied for more than 30 years [49], the roles of lipid metabolism reprogramming on invadopodia are still in early stage. In virtue of living cell imaging, invadopodia was recently confirmed as a special microdomain on membrane enriched with phospholipid PI $(4,5) \mathrm{P} 2$ and cholesterol. Our results also revealed that upregulation of cholesterol significantly increase membrane fluidity accompanied with Cortactin aggregation, suggesting that lipid metabolism is involved in the formation of invadopodia, and thus promote tumor cell metastasis $[50,51]$. These results might open up a new perspective of lipid metabolism on tumor metastasis.
MiRNAs have been confirmed as important players in HCC metastasis using post-transcriptional mechanism [19]. In our previous studies, we revealed that miR-612 had pleiotropic inhibitory effects on cell proliferation, EMT, stemness, and metastasis of HCC via directly suppressing akt2 expression [19]. In the present study, we found that hadha is another pivotal gene in miR-612 target network by RNA immunoprecipitation, RNA-seq, and luciferase report assay. A large amount of acetyl-CoA and ATP are produced by $\beta$-oxidation of long-chain fatty acids [52], resulting in many cancerous functions, such as autophagy [53], apoptosis [54], and so on. Here, we report a novel function of miR-612 on HCC invadopodia. Upregulation of miR-612 can significantly reduce cholesterol level and membrane fluidity of HCC, meanwhile, remarkably reduced the expressed level and function of Cortactin and Caveolin-1 in HCC invadopodia. Similar results were observed in HCC cells treated with $\beta$-oxidation inhibitor. Moreover, Wnt signaling pathway is able to lead to an increase in synaptic Cortactin and associated with cytoskeleton organization. Our finding also indicates that Cortactin is downstream of Wnt signaling, and associated to other cancer type s[47]. Our findings confirmed that miR-612 suppressed migration and invasion of HCC partially by HADHA-mediating lipid reprogramming and inhibited the formation of invadopodia and $\mathrm{Wnt} / \beta$-catenin-regulated EMT progression.

\section{Conclusion}

In summary, our study revealed that miR-612 negatively regulated invadopodia formation, matrix degradation, EMT, and metastasis of HCC by HADHA-mediated lipid reprogramming. The decreased miR-612 in HCC cells resulted in HADHA upregulation and initiated $\beta$-oxidation activities of fatty acids to supply sufficient acetyl-CoA, ATP for cholesterol biosynthesis via SREBP2/HMGCR cascade, which consequently affected HCC metastasis via lipid rafts and invadopodia. Here, we provide another new evidence of miR612 as a tumor suppressor microRNA in HCC. The issue is not only conducive to a comprehensive understanding of the role of miR-612 but also lays a theoretical foundation for metastatic HCC diagnosis and prevention based on miR-612. 


\section{Supplementary information}

Supplementary information accompanies this paper at https://doi.org/10. 1186/s13045-019-0841-3.

Additional file 1:. Figure S1. (A) Target genes and signaling pathways of miR-612 predicted by bioinformatics analyses. Red spot stands for HADHA. (B) Quality distribution of RNA pulled down by biotin-labeled miR-612 for RNA-seq analyses. (C) Base distribution of RNA pulled down by biotin-labeled miR-612 for RNA-seq analyses. (D-F) GO analyses of differential down-regulated genes based on their molecular function, cellular component and biological process.

Additional file 2: Figure S2. (A) HepG2 and HCCLM3 cells infected with hadha overexpression or knockdown lentivirus respectively. WT represents wild type cell line without any treatment. NC samples means the cell lines treated with negative control lentivirus. Scale bars, $200 \mu \mathrm{m}$. ( $B$ and $C$ ) The mRNA and protein levels of HADHA were tested by realtime PCRs and Western blots. ( $D$ and $E$ ) Fluorescence images of invadopodia staining by 647 (Cortactin) and FITC (phalloidin) in HCCLM3 ${ }^{\text {miR-612-OE }}$ and HCCLM3 ${ }^{\text {hadha-KD }}$ cells. $\left.{ }^{* * *} p<0.001\right)$. Data are mean \pm SEM of three independent experiments. Scale bars, $15 \mu \mathrm{m}$.

Additional file 3: Figure S3. (A and B) Tumor sizes and statistic results of subcutaneous HCCLM3 $3^{\mathrm{NC}}$ and HCCLM3 ${ }^{\text {hadha-KD }}$ xenografts. (C) Tumor sizes of HCCLM3 $3^{\mathrm{NC}}$ and HCCLM3 $3^{\text {hadha-KD }}$ xenografts in liver. (D) Standard plots of Acetyl CoA $\left(^{*} p<0.05\right)$.

Additional file 4. Exel file. The original data of mir-612-targeted genes available via RNA immunoprecipitation which up- or down-regulated significantly.

Additional file 5: Table S1. Primers sequences of PCR. Table S2. Reaction Mixes for Acetyl-Coenzyme A Assay (unit: $\mu$ l). Table S3. ATP detection operation rules (unit: $\mu$ l). Table S4. Reaction mixes for cholesterol quantitation assay (unit: $\mu l)$.

Additional file 6. Other materials and methods.

\section{Abbreviations}

AFP: Alpha-fetoprotein; CPT-1: Carnitine palmitoyl transferase-1.

EMT: Epithelial to mesothelial transformation; ETO: Etomoxir;

FISH: Fluorescence in situ hybridization; FP: Fluorescence polarization;

HADHA: Hydroxyacyl-CoAdehydrogenase/3-ketoacyl-CoAthiolase/enoyl-CoA

hydratase, alpha subunit; HCC: Hepatocellular carcinoma; $\mathrm{H}-\mathrm{E}$

staining: Hematoxylin-eosin staining; HK: Hexokinase; HMGCR: 3-Hydroxy-3methylglutaryl-CoA reductase; HMGCS1: 3-Hydroxy-3-methylglutaryl-CoA synthase 1; IHC: Immunological histological chemistry; IOD: Integrated optical density; KEGG: Kyoto encyclopedia of genes and genomes; LCHAD: Longchain 3-hydroxyacyl-CoA dehydrogenase; miRNA: Micro-RNA;

MVD: Mevalonate diphosphate decarboxylase; MBCD: Methyl- $\beta$-cyclodextrin; NA: Not available; NS: No significant difference; OCR: Oxygen consumption rate; OS: Overall survival; PFK: Phosphofructokinase; PFS: Progress-free survival; SQLE: Squalene epoxidase; TMA: Tissue microarray; TNM: Tumornode-metastasis

\section{Acknowledgments}

Not applicable.

\section{Authors' contributions}

$Y L$ performed cell line culture, Gelatin Invadopodia Assay, $\beta$-oxidation activity detection, Acetyl-Coenzyme A, ATP and Cholesterol Quantitation Assay, statistical analysis, and wrote the paper; LLL performed the in vitro cell migration, Western blot, mechanism exploration, and helped write the paper; DMG finished xenograft assays; LLD was responsible for the IHC assay; DLL performed TMA-DPH assay; XYB did the RT-PCR assay; WZW designed this project and supervised this project; JZ and JF provided technical support, human tissue chip, and clinical data. All authors read and approved the final manuscript.

\section{Funding}

The project was funded by the National Science Foundation of China (81272437, 81472675), National Key Research and Development Plan (2016YFC0902400), and Shanghai Municipal Health Commission, Collaborative Innovation Cluster Project (2019CXJQ02).

\section{Availability of data and materials}

Not applicable.

\section{Ethics approval and consent to participate}

The Ethics Committee of the Zhongshan Hospital Biomedical Research Department provided ethical approval, and informed consent for collecting and preserving samples and details was obtained from each patient. Xenograft experiments in nude nice were approved by the Animal Experimentation Ethics Committee of Zhongshan Hospital, Fudan University.

\section{Consent for publication}

Not applicable.

\section{Competing interests}

The authors declare that they have no competing interests.

\section{Author details}

'Liver Cancer Institute, Zhongshan Hospital, Key Laboratory of Carcinogenesis and Cancer Invasion, Ministry of Education, Fudan University, 180 Fenglin Road, Shanghai 200032, China. ${ }^{2}$ Department of Oral Maxillofacial-Head and Neck Oncology, Shanghai Ninth People's Hospital, School of Medicine, Shanghai Jiao Tong University, Shanghai, China. ${ }^{3}$ Department of Head and Neck Surgery, Fudan University Shanghai Cancer Center, Shanghai 200032, China. ${ }^{4}$ Department of Radiation Oncology, Shanghai General Hospital, Shanghai Jiaotong University, Shanghai 200080, China. ${ }^{5}$ Department of Liver Surgery and Transplantation, Zhongshan Hospital, Fudan University, Shanghai 200032, China.

Received: 3 September 2019 Accepted: 23 December 2019 Published online: 07 February 2020

\section{References}

1. Siegel RL, Miller KD, Jemal A. Cancer statistics, 2018. CA Cancer J Clin. 2018; 68:7-30. https://doi.org/10.3322/caac.21442.

2. Forner A, Llovet JM, Bruix J. Hepatocellular carcinoma. Lancet. 2012;379: 1245-55. https://doi.org/10.1016/S0140-6736(11)61347-0.

3. Vander Heiden MG, Cantley LC, Thompson CB. Understanding the Warburg effect: the metabolic requirements of cell proliferation. Science. 2009;324: 1029-33. https://doi.org/10.1126/science.1160809.

4. Perez-Escuredo J, Dadhich RK, Dhup S, Cacace A, Van Hee VF, De Saedeleer CJ, Sboarina M, Rodriguez F, Fontenille MJ, Brisson L, et al. Lactate promotes glutamine uptake and metabolism in oxidative cancer cells. Cell Cycle. 2016; 15:72-83. https://doi.org/10.1080/15384101.2015.1120930.

5. Mancini R, Noto A, Pisanu ME, De Vitis C, Maugeri-Sacca M, Ciliberto G. Metabolic features of cancer stem cells: the emerging role of lipid metabolism. Oncogene. 2018;37:2367-78. https://doi.org/10.1038/s41388-018-0141-3.

6. Fedida-Metula S, Feldman B, Koshelev V, Levin-Gromiko U, Voronov E, Fishman D. Lipid rafts couple store-operated $\mathrm{Ca} 2+$ entry to constitutive activation of PKB/Akt in a Ca2+/calmodulin-, Src- and PP2A-mediated pathway and promote melanoma tumor growth. Carcinogenesis. 2012;33: 740-50. https://doi.org/10.1093/carcin/bgs021.

7. Cai D, Wang J, Gao B, Li J, Wu F, Zou JX, Xu J, Jiang Y, Zou H, Huang Z, et al. RORgamma is a targetable master regulator of cholesterol biosynthesis in a cancer subtype. Nat Commun. 2019;10:4621. https://doi. org/10.1038/s41467-019-12529-3.

8. Leong HS, Robertson AE, Stoletov K, Leith SJ, Chin CA, Chien AE, Hague MN, Ablack A, Carmine-Simmen K, McPherson VA, et al. Invadopodia are required for cancer cell extravasation and are a therapeutic target for metastasis. Cell Rep. 2014:8:1558-70. https://doi.org/10.1016/j.celrep.2014.07.050.

9. Murphy DA, Courtneidge SA. The 'ins' and 'outs' of podosomes and invadopodia: characteristics, formation and function. Nat Rev Mol Cell Biol. 2011;12:413-26. https://doi.org/10.1038/nrm3141.

10. Sharma VP, Eddy R, Entenberg D, Kai M, Gertler FB, Condeelis J. Tks5 and SHIP2 regulate invadopodium maturation, but not initiation, in breast carcinoma cells. Curr Biol. 2013;23:2079-89. https://doi.org/10.1016/j.cub.2013.08.044.

11. Jacob A, Prekeris R. The regulation of MMP targeting to invadopodia during cancer metastasis. Front Cell Dev Biol. 2015;3:4. https://doi.org/10.3389/fcell. 2015.00004

12. Beltran-Anaya FO, Cedro-Tanda A, Hidalgo-Miranda A, Romero-Cordoba SL. Insights into the regulatory role of non-coding RNAs in cancer metabolism. Front Physiol. 2016;7:342. https://doi.org/10.3389/fphys.2016.00342. 
13. Christensen LL, True K, Hamilton MP, Nielsen MM, Damas ND, Damgaard CK, Ongen $\mathrm{H}$, Dermitzakis $\mathrm{E}$, Bramsen JB, Pedersen JS, et al. SNHG16 is regulated by the Wnt pathway in colorectal cancer and affects genes involved in lipid metabolism. Mol Oncol. 2016;10:1266-82. https://doi.org/10.1016/j.molonc. 2016.06.003

14. Cui M, Xiao Z, Wang Y, Zheng M, Song T, Cai X, Sun B, Ye L, Zhang X. Long noncoding RNA HULC modulates abnormal lipid metabolism in hepatoma cells through an miR-9-mediated RXRA signaling pathway. Cancer Res. 2015; 75:846-57. https://doi.org/10.1158/0008-5472.CAN-14-1192.

15. Ambros $V$. The functions of animal microRNAs. Nature. 2004;431:350-5. https://doi.org/10.1038/nature02871.

16. Bartel DP. MicroRNAs: genomics, biogenesis, mechanism, and function. Cell. 2004:116:281-97.

17. Flowers E, Froelicher ES, Aouizerat BE. MicroRNA regulation of lipid metabolism. Metabolism. 2013;62:12-20. https://doi.org/10.1016/j.metabol. 2012.04.009

18. Rottiers $V$, Naar AM. MicroRNAs in metabolism and metabolic disorders. Nat Rev Mol Cell Biol. 2012;13:239-50. https://doi.org/10.1038/nrm3313.

19. Tao ZH, Wan JL, Zeng LY, Xie L, Sun HC, Qin LX, Wang L, Zhou J, Ren ZG, Li $Y X$, et al. miR-612 suppresses the invasive-metastatic cascade in hepatocellular carcinoma. J Exp Med. 2013;210:789-803. https://doi.org/10. 1084/jem.20120153.

20. Rector RS, Payne RM, Ibdah JA. Mitochondrial trifunctional protein defects: clinical implications and therapeutic approaches. Adv Drug Deliv Rev. 2008; 60:1488-96. https://doi.org/10.1016/j.addr.2008.04.014.

21. Tang ZY, Sun FX, Tian J, Ye SL, Liu YK, Liu KD, Xue Q, Chen J, Xia JL, Qin LX, et al. Metastatic human hepatocellular carcinoma models in nude mice and cell line with metastatic potential. World J Gastroenterol. 2001;7:597-601.

22. Li Y, Tang ZY, Ye SL, Liu YK, Chen J, Xue Q, Chen J, Gao DM, Bao WH. Establishment of cell clones with different metastatic potential from the metastatic hepatocellular carcinoma cell line MHCC97. World J Gastroenterol. 2001;7:630-6.

23. Tang J, Tao ZH, Wen D, Wan JL, Liu DL, Zhang S, Cui JF, Sun HC, Wang L, Zhou J, et al. MiR-612 suppresses the stemness of liver cancer via Wnt/betacatenin signaling. Biochem Biophys Res Commun. 2014:447:210-5. https:// doi.org/10.1016/j.bbrc.2014.03.135.

24. Liu Y, Liu DL, Dong LL, Wen D, Shi DM, Zhou J, Fan J, Wu WZ. miR-612 suppresses stem cell-like property of hepatocellular carcinoma cells by modulating Sp1/Nanog signaling. Cell Death Dis. 2016;7:e2377. https://doi. org/10.1038/cddis.2016.282.

25. Artym W, Yamada KM, Mueller SC. ECM degradation assays for analyzing local cell invasion. Methods Mol Biol. 2009;522:211-9. https://doi.org/10. 1007/978-1-59745-413-1_15.

26. Landgraf $P$, Rusu M, Sheridan R, Sewer A, lovino N, Aravin A, Pfeffer S, Rice A, Kamphorst AO, Landthaler $\mathrm{M}$, et al. A mammalian microRNA expression atlas based on small RNA library sequencing. Cell. 2007;129:1401-14. https:// doi.org/10.1016/j.cell.2007.04.040.

27. Yuan JH, Yang F, Wang F, Ma JZ, Guo YJ, Tao QF, Liu F, Pan W, Wang TT, Zhou CC, et al. A long noncoding RNA activated by TGF-beta promotes the invasion-metastasis cascade in hepatocellular carcinoma. Cancer Cell. 2014 25:666-81. https://doi.org/10.1016/j.ccr.2014.03.010.

28. Tavazoie SF, Alarcon C, Oskarsson T, Padua D, Wang Q, Bos PD, Gerald WL, Massague J. Endogenous human microRNAs that suppress breast cancer metastasis. Nature. 2008:451:147-52. https://doi.org/10.1038/nature06487.

29. Yang XR, Xu Y, Yu B, Zhou J, Qiu SJ, Shi GM, Zhang BH, Wu WZ, Shi YH, Wu B, et al. High expression levels of putative hepatic stem/progenitor cell biomarkers related to tumour angiogenesis and poor prognosis of hepatocellular carcinoma. Gut. 2010;59:953-62. https://doi.org/10.1136/gut.2008.176271.

30. Zhu XD, Zhang JB, Zhuang PY, Zhu HG, Zhang W, Xiong YQ, Wu WZ, Wang $L$, Tang $Z Y$, Sun HC. High expression of macrophage colony-stimulating factor in peritumoral liver tissue is associated with poor survival after curative resection of hepatocellular carcinoma. J Clin Oncol. 2008;26:270716. https://doi.org/10.1200/JCO.2007.15.6521.

31. Xiao CL, Tao ZH, Guo L, Li WW, Wan JL, Sun HC, Wang L, Tang ZY, Fan J, Wu WZ. Isomalto oligosaccharide sulfate inhibits tumor growth and metastasis of hepatocellular carcinoma in nude mice. BMC Cancer. 2011;11: 150. https://doi.org/10.1186/1471-2407-11-150.

32. Thomson JM, Parker J, Perou CM, Hammond SM. A custom microarray platform for analysis of microRNA gene expression. Nat Methods. 2004;1:4753. https://doi.org/10.1038/nmeth704.
33. Tian J, Tang ZY, Ye SL, Liu YK, Lin ZY, Chen J, Xue Q. New human hepatocellular carcinoma (HCC) cell line with highly metastatic potential (MHCC97) and its expressions of the factors associated with metastasis. Br J Cancer. 1999:81:814-21. https://doi.org/10.1038/sj.bjc.6690769.

34. Yamaguchi H, Takeo Y, Yoshida S, Kouchi Z, Nakamura Y, Fukami K. Lipid rafts and caveolin-1 are required for invadopodia formation and extracellular matrix degradation by human breast cancer cells. Cancer Res. 2009;69:8594-602. https://doi.org/10.1158/0008-5472.CAN-09-2305.

35. Caldieri G, Giacchetti G, Beznoussenko G, Attanasio F, Ayala I, Buccione R. Invadopodia biogenesis is regulated by caveolin-mediated modulation of membrane cholesterol levels. J Cell Mol Med. 2009;13:1728-40. https://doi. org/10.1111/j.1582-4934.2008.00568.x.

36. Maeyashiki C, Oshima S, Otsubo K, Kobayashi M, Nibe $Y$, Matsuzawa $Y$, Onizawa M, Nemoto Y, Nagaishi T, Okamoto R, et al. HADHA, the alpha subunit of the mitochondrial trifunctional protein, is involved in long-chain fatty acid-induced autophagy in intestinal epithelial cells. Biochem Biophys Res Commun. 2017:484:636-41. https://doi.org/10.1016/j.bbrc.2017.01.159.

37. Egnatchik RA, Leamy AK, Noguchi Y, Shiota M, Young JD. Palmitate-induced activation of mitochondrial metabolism promotes oxidative stress and apoptosis in H4llEC3 rat hepatocytes. Metabolism. 2014;63:283-95. https:// doi.org/10.1016/j.metabol.2013.10.009.

38. Grundner M, Zemljic JS. Cytoskeleton modification and cholesterol depletion affect membrane properties and caveolae positioning of $\mathrm{CHO}$ cells. J Membr Biol. 2014;247:201-10. https://doi.org/10.1007/s00232-013-9625-9.

39. Fielding CJ, Fielding PE. Cholesterol and caveolae: structural and functional relationships. Biochim Biophys Acta. 2000;1529:210-22. https://doi.org/10. 1016/s1388-1981(00)00150-5.

40. Incardona JP, Eaton S. Cholesterol in signal transduction. Curr Opin Cell Biol. 2000;12:193-203.

41. Seano G, Primo L. Podosomes and invadopodia: tools to breach vascular basement membrane. Cell Cycle. 2015;14:1370-4. https://doi.org/10.1080/ 15384101.2015.1026523.

42. Yamaguchi H, Lorenz M, Kempiak S, Sarmiento C, Coniglio S, Symons M, Segall J, Eddy R, Miki H, Takenawa T, Condeelis J. Molecular mechanisms of invadopodium formation: the role of the N-WASP-Arp2/3 complex pathway and cofilin. J Cell Biol. 2005;168:441-52. https://doi.org/10.1083/jcb.200407076.

43. Burger KL, Learman BS, Boucherle AK, Sirintrapun SJ, Isom S, Diaz B, Courtneidge SA, Seals DF. Src-dependent Tks5 phosphorylation regulates invadopodia-associated invasion in prostate cancer cells. Prostate. 2014;74: 134-48. https://doi.org/10.1002/pros.22735.

44. Zhang Y, Nolan M, Yamada H, Watanabe M, Nasu Y, Takei K, Takeda T. Dynamin2 GTPase contributes to invadopodia formation in invasive bladder cancer cells. Biochem Biophys Res Commun. 2016:480:409-14. https://doi. org/10.1016/j.bbrc.2016.10.063.

45. Baek AE, YU YA, He S, Wardell SE, Chang CY, Kwon S, Pillai RV, McDowell HB, Thompson JW, Dubois LG, et al. The cholesterol metabolite 27 hydroxycholesterol facilitates breast cancer metastasis through its actions on immune cells. Nat Commun. 2017:8:864. https://doi.org/10.1038/s41467017-00910-z.

46. Liu L, Li MY, Xing Y, Wang XY, Wang Y. The oncogenic roles of 27hydroxycholesterol in glioblastoma. Oncol Lett. 2019;18:3623-9. https://doi. org/10.3892/ol.2019.10690.

47. Cairns RA, Harris IS, Mak TW. Regulation of cancer cell metabolism. Nat Rev Cancer. 2011;11:85-95. https://doi.org/10.1038/nrc2981.

48. Carracedo A, Cantley LC, Pandolfi PP. Cancer metabolism: fatty acid oxidation in the limelight. Nat Rev Cancer. 2013;13:227-32. https://doi.org/ $10.1038 /$ nrc3483.

49. Attanasio F, Caldieri G, Giacchetti G, van Horssen R, Wieringa B, Buccione R. Novel invadopodia components revealed by differential proteomic analysis. Eur J Cell Biol. 2011;90:115-27. https://doi.org/10.1016/j.ejcb.2010.05.004.

50. Wang C, Yoo Y, Fan H, Kim E, Guan KL, Guan JL. Regulation of integrin beta 1 recycling to lipid rafts by Rabla to promote cell migration. J Biol Chem. 2010;285:29398-405. https://doi.org/10.1074/jbc. M110.141440.

51. Li J, Gu D, Lee SS, Song B, Bandyopadhyay S, Chen S, Konieczny SF, Ratliff $\mathrm{TL}$, Liu X, Xie J, Cheng JX. Abrogating cholesterol esterification suppresses growth and metastasis of pancreatic cancer. Oncogene. 2016:35:6378-88. https://doi.org/10.1038/onc.2016.168.

52. Aoyama T, Wakui $K$, Orii KE, Hashimoto T, Fukushima Y. Fluorescence in situ hybridization mapping of the alpha and beta subunits (HADHA and $\mathrm{HADHB}$ ) of human mitochondrial fatty acid beta-oxidation multienzyme complex to 2p23 and their evolution. Cytogenet Cell Genet. 1997;79:221-4. 
53. Behrends C, Sowa ME, Gygi SP, Harper JW. Network organization of the human autophagy system. Nature. 2010;466:68-76. https://doi.org/10.1038/ nature09204.

54. Zhang L, Zhang W, Wang YF, Liu B, Zhang WF, Zhao YF, Kulkarni AB, Sun ZJ.

Dual induction of apoptotic and autophagic cell death by targeting survivin in head neck squamous cell carcinoma. Cell Death Dis. 2015;6:e1771.

https://doi.org/10.1038/cddis.2015.139.

\section{Publisher's Note}

Springer Nature remains neutral with regard to jurisdictional claims in published maps and institutional affiliations.

Ready to submit your research? Choose BMC and benefit from:

- fast, convenient online submission

- thorough peer review by experienced researchers in your field

- rapid publication on acceptance

- support for research data, including large and complex data types

- gold Open Access which fosters wider collaboration and increased citations

- maximum visibility for your research: over $100 \mathrm{M}$ website views per year

At BMC, research is always in progress.

Learn more biomedcentral.com/submissions 